\title{
The use of anisotropic texturing for control of directional friction
}

\author{
Ping Lu ${ }^{1}$, , Robert J.K Wood ${ }^{1}$, Mark G. Gee ${ }^{2}$, Ling Wang ${ }^{1}$, Wilhelm Pfleging ${ }^{3}$ \\ 1 National Centre for Advanced Tribology at Southampton SO17 1BJ, Southampton; lupingping719@gmail.com; \\ r.wood@soton.ac.uk; ling.wang@soton.ac.uk \\ 2 National Physical Laboratory, TW11 0LW, Teddington; mark.gee@npl.co.uk \\ 3 Karlsruhe Nano Micro Facility; Hermann-von-Helmholtz-Platz 1, 76344 Egg.-Leopoldshafen, Germany; \\ wilhelm.pfleging@kit.edu \\ * Correspondence: lupingping719@gmail.com; Tel.: +44-772-4709-480
}

\begin{abstract}
This paper presents a study on the influence of anisotropically shaped texture arrays on friction behaviour of an oil lubricated sliding contact, especially on directional friction control based on the diverging and converging characteristics of the textures. Experiments have been conducted on a TE77 reciprocating cylinder-on-plate test rig, where steel rollers were used to slide against steel plate samples with or without textures. A mineral base oil was used to lubricate the contacts. Three geometries of dimples were designed and laser textured on the steel plate samples with varied 3-dimensional features, including Square Flat (SF), Square slope (SS) and Triangular Flat (TF) shapes representing the shape in $\mathrm{x}-\mathrm{y}$ (top view) and $\mathrm{x}-\mathrm{z}$ (side view) planes respectively. These shapes were chosen to vary the converging and diverging properties of the lubricated contacts depending on the sliding direction. Relatively large dimple sizes (side length $\sim 500 \mu m$ and depth $\sim 10 \mu \mathrm{m}$ ) have been used in this study to enable observation of the effect and easy control of the texturing process. The texture density has been kept at $10 \%$ as most literature suggested. The large dimple sizes resulted that the dimples were not be fully covered by the contact area, i.e. the dimple sides were bigger than the Hertzian contact width of the roller-flat contacts. This has eliminated the 'lift' or 'load bearing' effect discussed in most papers thus focuses on other effects investigated in this study. The results show that beneficial effects of the anisotropic textures present in all lubrication regimes including the boundary, mixed and hydrodynamic lubrications, especially under prevailing boundary lubrication conditions. Using high sampling rate for the friction data during the tests, it was able to study local friction effect due to individual dimple array especially at their leading and trailing edges. The results show that a local friction reduction is observed at the leading while an increase at the trailing edge. Overall directional friction effect of the anisotropic textures has been observed that the converging shape in both $y-z$ plane and the $x-y$ plane reduces friction. Furthermore, it was found that the triangular shape dimples have a greater local frictional response at each dimple array, while the sloped bottom square dimples have a more significant overall directional fricition effect.
\end{abstract}

Keywords: dimple shape; directional effect; friction reduction; laser surface texturing; reciprocating sliding 


\section{Introduction}

It has been known for decades that topography of rubbing surfaces has major influences on their frictional behaviour. Surface texturing is one of the most widely used technique to modify surface topography thus reduce or increase friction depending on the applications. The majority of applications benefit from friction reduction [1], while others can benefit from increased friction. For example, a car tyre is required to provide a firm grip on the road, especially in wet conditions, hence the treads on the tyre surface is designed to squeeze water out of the contact thus avoid skidding or hydroplaning [2]. The history of using textures to enhance grip can be traced back to the first pair of shoes with patterned soles, while the consideration of using textured surface to reduce friction probably only started in 1966 [3] when Hamilton proposed a theory to explain the extra hydrodynamic pressure generated by micro-irregularities on mechanical seals working under parallel sliding lubrication conditions. The research in textured surfaces for friction reduction only widely started from 1996 when Etsion's group showed significant effects of textured surface through the modelling of textured surfaces [4].

Over the past 20 years, over 400 papers have been published reporting studies on surface texturing, covering both experimental and theoretical investigations [5]. Majority studies have been focused on modelling of textured surfaces based on different forms of the Reynolds equation, Navier-Stokes equations or Stokes equations. Basic models for various applications, like journal bearings [6], mechanical seals [7], thrust bearings [8] and cylinder liners [9], have been built to find the optimal texture designs. In the meantime, a significant number of experimental studies have been conducted using both traditional tribometers (unidirectional pin-on-disc [10-14] or reciprocating sliding [15-19] test set-up) and real components (including journal bearings [20] thrust bearings [2123] and mechanical seals [24]). For the textured surface in terms of friction and wear reduction, the following mechanisms were proposed to explain the phenomenon observed in the experimental tests: 1. Debris-trapping under dry and boundary lubrication conditions to reduce third-body wear [5, 25, 26]; 2 Lubricant reservoir under boundary and mixed lubrication conditions which give secondary lubrication to prevent lubricant starvation [27, 28]; 3. Micro-hydrodynamic pressure build-up to increase load support, which can be estimated by solving the Reynolds [29, 30] or Navier-stokes equations [31, 32], also the pressure build-up effect was significantly affected the number of dimple edges [13], squeeze film effect [1] and cavitation phenomenon [33]. Moreover, the recent studies suggested that not only one factor works at one time [1,34], also the optimal texturing parameters are very dependent on the contact type between tribo-pairs, and the operating conditions. Consequently, the mechanism understanding of textured surfaces' friction behaviour is a key goal to achieve optimised dimple design for specific applications.

One of the interesting areas in texturing research is the influence of texture shapes (see Fig. 1 a, b, c, d), especially anisotropic dimple shapes. For examples, triangular [35-40] and chevron shapes [18, 41, 42] (shown in Fig. $1 \mathrm{c}$, and d). Both numerical and experimental results have shown that the dimple shape has a significant influence on the minimum film thickness and pressure distribution. The triangular and chevron pattern pointing to the sliding direction always get a better performance regarding of friction reduction effect with the largest film thickness. Apart from dimple shapes, the influence of internal shapes (cross-section shapes) of dimples has also been investigated, and Fig. 1 (i, ii, iii, iv) give examples of the different type of cross-section shapes. In 2008, Nanbu et al. studied numerically the rectangular shaped dimples with linearly varying bottom profile textures, which include Shape (b) with (i) and (iv) profiles in Fig.1. The elasto-hydrodynamic lubrication (EHL) modelling results showed that a larger hydrodynamic lifting effect generated with converging sloped bottom dimples than the flat bottom one [43]. Unanimous conclusions were achieved by another modelling work [44] using both Reynold's equations and computational fluid dynamics (CFD) simulation by Han et al. in 2011. Notably, different results 
were generated from an experimental and numerical work by Shen and Khonsari in 2013 [45]. The aim of their work was to check the lubrication effectiveness of dimples with various internal structures. Three circular top profile and linearly varying bottom profile dimple designs (Shape (a) with (i), (iii), (iv) profile in Fig. 1) and two sets of parameters were tested. They found the dimple with the rectangular pattern (Shape (a) with (iv) profile) generated more load carrying capacity (LCC) than the other two triangular profiles (Shape (a) with (i), (iii) profiles). Moreover, the results showed that the effect of dimple profile on LCC produced by small dimples (diameter: $800 \mu \mathrm{m}$ ) were not as obvious as large dimples (diameter: $6000 \mu \mathrm{m}$ ). In a more recent experimental work published in 2016, sloped bottom circular dimples (Shape a with i profile) with varying converging angle were fabricated and tested by Schuh and Ewoldt [46], and the results were compared with the ones from symmetrical shaped dimples (Shape (a) with (iv) profile). The comparison of results suggested the effective friction coefficient of asymmetric shapes was lower than that of symmetric shapes, and there was an optimal angle for decreasing friction which depended on operating conditions. From the above literature of friction study on symmetric and asymmetric shaped dimples, Schuh's results agreed with Nanbu and Han's that asymmetric shaped dimples has lower friction, but was different to the results from Shen's that symmetric shaped dimples are more beneficial for friction reduction. Work on this aspect reported in the literature is still limited, and results are inconstant.

According to the literature, almost all of the study present the overall friction reduction effect of the textured surfaces, and the local friction response due to the entrainment from individual dimples or dimple arrays are rarely studied. Except for Vladescu's experiments [18], which captured the transient friction variation as individual rectangular pockets (length $\times$ breadth $\times$ depth: $1 \mathrm{~mm} \times 80 \mu \mathrm{m} \times 8 \mu \mathrm{m}$ ) passing through a reciprocating sliding contact. A steep reduction in friction force is observed as each pocket leaves the contact in boundary lubrication regime. They suggested that this local friction response presumably is caused by the abrupt increase in film thickness. While similar local friction effects were observed in previous work by the current authors [47], that the friction drops as soon as the dimple array enters the contact area, and upward steps at trailing edge cause a friction increase. It should be noted that, in Vladescu's study, the relatively narrow and long rectangular pockets were fully covered in the contact area while sliding, whereas the previous work by the current authors was conducted with uncapped square dimples.

In summary, directional friction effect has been observed in anisotropic surface texturing investigation [36], it is recognised that dimples geometry could be a major factor influencing friction behaviours. However, the mechanisms behind are still unclear, and the local friction response of dimple geometries needs to be further studied. To address this, the presented study aims to offer a systematic study of the properties of the textured surface in a range of test conditions for a better understanding of the mechanisms. Various geometries have been designed and fabricated on steel specimen using laser surface texturing technique, and the tribological tests have been conducted to characterise how friction reduction effect produced by the dimpled surfaces in reciprocating lubricated line contacts with base oil lubrication. High sampling rate acquisition system was employed to capture the transient friction, and the local friction response as the leading edge and trailing edges of individual anisotropic textured dimple array passing through the sliding contact area were successfully captured in the transient friction. The mechanism of how anisotropically textured geometry causing directional friction are discussed by analysing the transient friction results. This work can also serve as a basis for using anisotropic surface textures for developing decreasing friction in lubricated sliding contact models.

\section{Experimental details}




\subsection{Experimental apparatus}

As this study aims to investigate the influence of the converging and diverging texture shapes on friction,

reciprocating sliding tests enable the observation of friction of same features at both directions during one test, a reciprocating tribometer is selected to conduct the experimental tests. With the assistance of the high-speed data acquisition system, the transient friction of each stroke can be obtained and the local friction response of each texture array can be further analysed.

Both smooth and laser textured steel surfaces were tested against steel rollers using a cylinder-on-flat line contact configuration on a Plint TE77 reciprocating tribometer (Phoenix Tribology Ltd., Kingsclere, UK), as shown in the sketch in Fig. 2. Real-time measurements of root mean square (RMS) friction force were acquired using a Compend 2000 system at a data acquisition rate of $1 \mathrm{~Hz}$ during tests. Also, completed friction loops were recorded every 2 minutes at a sampling rate of $20 \mathrm{kHz}$.

During the tests, the roller was fixed onto an arm which was connected to an eccentric cam, rotating in an oil bath. The crankshaft system provided a pure sinusoidal reciprocating motion to the roller sliding against the lower specimen. The plate was kept stationary in the oil bath by two screws (the lower sample shown in Fig. 2b). The oil bath was mounted onto the machine, and a piezo-electric transducer was installed to measure the friction force which has a sensitivity of typically $45.7 \mathrm{pC} / \mathrm{N}$ in the range of $+/-500 \mathrm{~N}$.

\subsection{Specimens}

The plates, with a dimension: $60 \mathrm{~mm} \times 22 \mathrm{~mm} \times 4 \mathrm{~mm}$, were made out of the hardened ASP 2023 steel, and the hardness of them reached $800 \mathrm{HV}$ after heat treatment. The testing surface of the plates was ground and lapped to a roughness around $R_{a}=0.01 \mu \mathrm{m}$ before texturing. The cylindrical roller (Bearingboys, Norwich, UK), with a diameter of $6 \mathrm{~mm}$ and length of $10 \mathrm{~mm}$, was made out of bearing steel AISI 52100 with hardness of approximately $850 \mathrm{HV}$ and a surface roughness of $0.03 \mu \mathrm{m}$. The roughness was measured by a Taylor Hobson Form Talysurf 120L stylus profilometer (Taylor Hobson Ltd., Leicester, UK).

In this work, three dimple geometries (square flat (SF), square slope (SS), and equilateral triangular flat (TF)) were fabricated on the plate samples and tested. These three types of dimples were designed with same dimple side length and depth at the innermost. The square sloped dimple has a linearly varying bottom profile is tested to investigate the lubrication effects of the dimple cross-section shape, while the triangular flat shape dimpled sample is to investigate the influence by top-view shapes. The sketches and design parameters of them are detailed in Table 1 with axes definition.

The textures were produced by laser surface texturing (LST) on the plate surfaces at Karlsruhe Nano Micro Facility. Ultrafast laser-structuring was carried out on a micromachining workstation (PS450-TO, Optec, Belgium) equipped with a tunable fiber laser (Tangerine, Amplitude Systèmes, France). A schematic diagram of the laser micromachining system can be found in [48]. The average power was $20 \mathrm{~W}$ and the maximum pulse energy was specified to $100 \mu \mathrm{J}$ at $1030 \mathrm{~nm}$ (TEM00 with M2 < 1.3). The pulse repetition rate could be varied from single pulse to $2 \mathrm{MHz}$ and the laser pulse duration from 380 fs to $10 \mathrm{ps}$, respectively. The laser beam scanned over the sample surface for all experiments using a Rhothor ${ }^{\mathrm{TM}}$ Laser Deflection Systems scan head (Newson Engineering BV). The laser wavelength can be varied from near infrared (1030 nm, $1064 \mathrm{~nm})$ down to the UV (343 nm) region (Fig. 3). Dimple structures in Table 1 was textured with a laser wavelength of $1030 \mathrm{~nm}$, an average power of $0.45 \mathrm{~W}$, a repetition rate of $200 \mathrm{kHz}$, a pulse duration of $350 \mathrm{fs}$, and a scanning speed of 200 $\mathrm{mm} / \mathrm{s}$. The pitch between the two laser scanning paths was $10 \mu \mathrm{m}$. The ablation depth per scanning layer was measured to be $1 \mu \mathrm{m}$. Therefore, the $\mathrm{z}$-axis was always moved by a step size of $1 \mu \mathrm{m}$ between two layers to 
guarantee that the ablation depth per laser scan remains constant. All laser structuring processes were carried out under ambient air, and the ablated material was removed by an exhaust.

Also, the actual parameters are characterised by an optical microscope (Alicona Infinite-Focus, Alicona Imagine GmbH, 158 Raaba, Austria), and the measurements were listed in Table 2 with an example of single dimple topography. As can be seen from the three-dimensional profiles, all shapes dimples were finished with comparable accuracy without rims on their edges. For the square flat bottom dimples, the side length was $4 \%$ smaller than designed. Moreover, for the triangular flat dimples, the depth at the apex angle was around twice the designed depth due to the need for the edge to be scanned twice to ensure that a smooth line was obtained, which also extended the length of dimples in the sliding direction by around $10 \%$. The dimple bottoms were pretty smooth with an arithmetical mean deviation of the primary profile less than $1 \mu \mathrm{m}$. Five dimples for each sample were picked up randomly, and the consistency of isolated element texture in each sample was shown by the tolerances of measurements.

\subsection{Tribological testing}

Reciprocating sliding tests were conducted at room temperature with Vitrea 32 mineral base oil as the lubricant. The tests conducted with mineral base oil without additives will simply reflect the friction response to the feature topography rather than the effect by tribo films generated during tests. For each test, around $15 \mathrm{ml}$ oil was used to ensure that the plate specimen was fully submerged.

The dimpled surfaces and roller were aligned before testing to avoid partial contact occurrence between the frictional surfaces. During the test, a normal force of $100 \mathrm{~N}$ was initially applied to the $6 \mathrm{~mm}$ diameter roller, resulting in a Hertzian mean contact pressure of $0.28 \mathrm{GPa}$, with the initial Hertzian contact width at $36 \mu \mathrm{m}$. During the test, the sliding frequency was decreased stepwise from the highest $(15 \mathrm{~Hz})$ to the lowest $(1 \mathrm{~Hz})$ with a stroke length of $10 \mathrm{~mm}$, as shown in Fig. 2c. Every state was maintained for 8 mins except the $15 \mathrm{~Hz}$ conditions which lasted for $18 \mathrm{mins}$, as shown in Fig. 4. After $130 \mathrm{mins}$, the test was repeated once with the load increased to $350 \mathrm{~N}$ using the same roller against the same track. With the increased load, the Hertzian mean contact pressure and initial contact width increased to $0.52 \mathrm{GPa}$ and $68 \mu \mathrm{m}$, respectively. The contact widths of both conditions were smaller than the dimple width, as shown by red area in Fig. $2 \mathrm{c}$ and no dimple was fully covered by the roller during the tests.

The lubricant temperature was monitored using a thermocouple which fixed to the oil bath during the test, and the selected lubricant has the following properties under the stabilised testing temperature $\left(32 \pm 1^{\circ} \mathrm{C}\right)$ : pressure-viscosity coefficient $\alpha=12.8 \times 10^{-9} \mathrm{~m}^{2} / \mathrm{N}$, kinematic viscosity $v=48 \mathrm{~mm}^{2} / \mathrm{s}$, and the dynamic viscosity $\eta=0.042 \mathrm{~Pa} \cdot \mathrm{s}$. Under these test conditions, the minimum mid-stroke film thickness was calculated using Dowson and Higginson's equation [49] for line contacts. According to the calculations, the mid-stroke film thickness at the start of the test is $105 \mathrm{~nm}$ under $100 \mathrm{~N}$ load with $15 \mathrm{~Hz}$ sliding frequency, and the thickness drops to $13 \mathrm{~nm}$ at the end of the test whose load and frequency is $350 \mathrm{~N}$ load and $1 \mathrm{~Hz}$, respectively.

\section{Results and discussion}

For each of the three dimple designs, the procedure $(100 \mathrm{~N} \& 350 \mathrm{~N})$ described above was repeated twice with fresh roller and plate surfaces to confirm the repeatability of test results. The results are graphically depicted for various sliding frequency and load, with the extent of the reduction and orientation effects of the texture on friction. 


\subsection{Wear track examination}

The wear tracks on the plate surfaces were imaged using an Alicona microscope and the results are shown in

Fig. 5. The roller sliding directions (forward or backward) are marked together with the schematics of the dimple cross-section ( $\mathrm{x}-\mathrm{z}$ plane) shapes. It can be seen that the wear scar length is $10 \mathrm{~mm}$ (the stroke length), while the wear scar width is slightly shorter than the roller width $(10 \mathrm{~mm})$ due to the fillet at the ends of the rollers. Good alignments between the cylinder and flat surfaces were achieved, and the friction pairs were in full contact during tests. The starting and ending positions on the plate are obtained from the $\mathrm{x}-\mathrm{y}$ plane images and are summarised in Table 3. This data was used in the analysis of the single stroke friction especially with the dimple positions and their shapes for local friction characterisation.

To examine wear on the flat surface in more details, profiles of the worn surfaces scanned at positions marked (two red lines on each sample in $\mathrm{x}$ - and y-direction in Fig. 5) are shown in Fig. 6. Scans at non-tested areas close to the worn surfaces are performed as the baselines (blue lines in Fig. 6) for comparison with the worn surface profiles (red lines). For anisotropic dimpled surfaces, two y-direction profiles were imaged near the stroke ends to check whether asymmetric wear appeared, and the positions where profiles were taken are shown by the same colour used in Fig. 5. Based on the profile measurements, the maximum wear depth was found to be $100 \mathrm{~nm}$ in the square slope sample (see area circled by red in Fig. 6). The weight of each sample was measured before and after the frictional tests using a precise analytical balance for three times, which has an accuracy of $0.01 \mathrm{mg}$. It was found that the mass difference was below the limit of the accuracy of the instrument, thus the wear of the specimens is not significant.

The images of the wear scars of the tested cylinders are presented in Fig. 7. All samples have a similar wear scar width of $100 \mu \mathrm{m}$ with contact part above dimples are slightly harder worn than other parts. The wear volume was calculated using the cylinder radius to be $2.78 \times 10^{-13} \mathrm{~m}^{3}$. Since the total sliding distance for the upper cylinder was $2952 \mathrm{~m}$ (1476 $\mathrm{m}$ for each load), the wear rate was $4.2 \times 10^{-19} \mathrm{~m}^{2} / \mathrm{N}$. The above measurements lead to the conclusion that the wear volume of both textured plates and cylinders were minimal. Therefore, the wear debris trapping function of dimples is not applicable here in these experiments.

\subsection{Friction repeatability}

The biggest difference in the friction coefficient between two tests is around $3 \%$ for the smooth sample results, and less than $5 \%$ for textured sample results, confirming that the testing process is stable. In order to evaluate the stability of test set-up, examples of 0.5 -second friction responses and roller displacements versus time, under the test frequency of $10 \mathrm{~Hz}$ and the load of $100 \mathrm{~N}$ for both non-textured and textured tests, are presented in Fig. 8. The non-textured results are adapted from a paper published by the current authors [47]. Fig. 8 shows there is negligible variation for both friction and roller displacements over time for all specimens. Also, high frequency and low amplitude friction fluctuations can be seen in all friction recordings due to the unavoidable noise caused by fluctuations in load.

Note that the plus or minus sign of friction only indicates the roller's sliding direction instead of positive or negative friction values. The positive friction represents the friction generated when the roller was sliding towards the "backward" direction (marked by blue arrow in Fig.5), while the negative friction represents the "forward" direction (marked by pink in Fig.5). For the rectangular sloped textured samples, the roller sliding towards the "forward" direction is also called converging direction in the following discussion since the depth decreases linearly along the x-positive direction, and vice versa. Same definitions are also used for the triangular flat dimples. 


\subsection{Overall friction analysis}

During the test, both RMS friction and transient friction were captured under each test conditions. The RMS

friction is calculated by friction through whole strokes, while the transient friction along the stroke was recorded by the high-speed data acquisition system.

Take the results under $100 \mathrm{~N}$ and $10 \mathrm{~Hz}$ shown in Fig. 8 as examples, the average value of friction data within one feature spacing length in the stroke centre for each specimen is marked in the box. According to the lambda ratio calculations $(\lambda=2.8$ under $100 \mathrm{~N}$ and $10 \mathrm{~Hz})$, this test condition lies in the mixed to hydrodynamic lubrication condition, that both hydrodynamic lubrication and surface contact are significant. All the textured samples have a larger friction fluctuation compared to the non-textured specimen, which indicates the lubricant film's fluctuation between the cylinder and textured surfaces is much greater than that of smooth surfaces. Moreover, the friction magnitudes of anisotropic dimpled surfaces in opposite direction are significantly different: the diverging direction friction is always higher than that of the converging direction. Especially for the triangular dimpled sample, the diverging shape even increased the friction to a value higher than that of smooth surfaces under this condition. For these two anisotropic textured surfaces, the higher friction in diverging direction indicates that the lubricant film between frictional surfaces is thinner, and more asperites are coming into contact.

When performing tests under boundary lubrication conditions (e.g. $350 \mathrm{~N}$ and $2 \mathrm{~Hz}$, where $\lambda=0.8$ ), the majority of friction is caused by the asperities contacts between frictional pairs. To compare the differences in the friction at the two sliding directions, two lines are plotted against time in the same figure (Fig. 9), i.e. both start from the beginning of the stroke. While the little difference is observed between the results of these two directions for the smooth and square flat bottom dimples tests, and a continuous friction difference between these two directions is observed for the square slope and triangular flat dimple. As shown in Fig.9, the difference between trend lines (marked by dashed lines) of the square slope bottom dimples (around 8\%) are larger than that of triangular dimpls (around 5\%). In addition, periodic peaks and valleys are seen in all textured surface, and the number of period agrees with the number of dimple arrays ( 6 for square textured samples, 9 for triangular textured samples), which suggests that local friction responses being observed are related to the dimple arrays.

As it is reciprocating motion, the roller speed variation follows a sinusoid shape; the sliding speed curve is symmetrically disposed about the central of a stroke, where the highest speed achieved at the mid-stroke. The reversal stroke took place at $x$ positions of $-5 \mathrm{~mm}$ and $5 \mathrm{~mm}$, where the speed was $0 \mathrm{~mm} / \mathrm{s}$. However, the overall shape of the friction curves is asymmetrical due to squeezing film effects, where the oil was entrapped between contacting surfaces at both ends of the stroke, and better lubrication took place at the starting point of each stroke with recropcating motion [50]. Besides, the friction in accelerating process is always higher than that of the decelerating process at the same rate, which agrees with observations by Costa et al. [41] and Vladescu et al. [18].

To sum up, a clear directional friction effect has been observed with anisotropically textured samples in both boundary lubrication and mixed to hydrodynamic lubrication conditions, and the converging direction friction is always lower than that of the diverging directions. The overall directional friction effect suggests that the lubricant film thickness enhanced by converging geometry is better than that provided by a diverging geometry. This agrees with the findings of previous research, such as the pressure distribution modelling work under mixed lubrication regime by Hui Zhang who suggested that much denser contacts and thinner films will be obtained when triangular textures sliding in the diverging direction [39]. Also, Bo Zhang mentioned that the existence of dimples might lead to an increase of contact stress appearing at the edges of dimples [51], and the stress, caused by deformation, ploughing or cutting while sliding, could also increase the friction force. Other than these two modelling studies 
focusing on area contacts, this study also confirmed that the line-contact has a great impact on the directional friction and the friction amplitude is consistent with the area contact situation.

\subsection{Local friction response caused by real contact length}

As illustrated in Section 3.3, clearly transient friction response due to the existence of textures is observed under boundary lubrication regimes. Fig. 10 compared the variation in friction force along a single stroke for the smooth and the textured specimens, all under a constant load of $350 \mathrm{~N}$. The friction values from four strokes in each test have been averaged to reduce the noise influence. It should be noted that less than $3 \%$ friction difference was found among stroke 1 to stroke 4 (with the maximum friction variation at each sampling point), and there is no obvious increase or decrease in mid-stroke friction along the test duration under the same test condition. For all textured specimens, the pink areas that bordered with dashed lines indicated the dimples' locations according to the wear track measurement records presented in Table 3. It can be seen that an apparent reduction in friction appears when the sliding frequency increase. This could be caused by the growth in the minimum film thickness. But the local friction response for each specimen are always following the same variation trend, and the local friction response correlates closely to the dimple array's position.

To examine the effect on a single column of dimples within an array, the trend in the friction traces (under $350 \mathrm{~N}, 2 \mathrm{~Hz}$ ) was removed by subtracting the trend line, and the results are summarised in the Table. 4. The local friction responses of square slope dimples were similar to those of the square flat dimples, that the local friction responses are similar when the roller is sliding in opposite direction, and there are no obvious friction variation changes can be observed when changing the dimple's bottom shape. While for the triangular flat dimples, the local friction responses of opposite sliding directions are totally different. The above results suggest that the top-view shape variation is the major factor that causing the local friction fluctuation, since the top-view shapes have a great impact on the real contact length between textured samples and roller.

As shown in Fig. 2c, the real contact length between sample and roller is marked by red lines, which is calculated from the length of the roller subtracted by the dimples length. When a roller is sliding on a textured sample, the real contact length between roller and surface varies with the location (displacement) of the roller, and the relationship can be present by the curve showed in Fig. 11. The real contact length for the square dimples follows a rectangular function, and it is independent of the roller sliding direction. While for the triangular shaped dimples, the real contact length's variation depends on the roller's sliding direction. From Table. 4, it can be seen that the leading edge of all texture shape is introducing friction reduction, while the trailing edge promotes friction increase, which suggests a lower contact length is beneficial for local friction reduction. However, it should also be noted that the Hertzian contact pressure varied with the real contact length, that contact pressures were higher when the roller was sliding just above each column of dimples, and the semi-contact width became wider than that of the roller above the gap between dimple columns. Therefore, the lubricant film is thinner for the samples with smaller real contact length above the dimple arrays, which could make total friction increase.

Combine with the directional friction effect observed in Fig. 9, the converging shape at the base of the dimple should have enhanced the total lubrication effect, where the lubricant inside the dimples is easier to be squeezed out along the slope form for secondary lubrication in the boundary lubrication regime. Therefore a continuous lubricant film is easier to be formed when the roller is sliding towards the converging direction. In contrast, when the roller is sliding towards the diverging direction, the edges of dimples collapse the lubricant film. Also, it may be caused by the cavitation phenomenon observed by Vladescu et al. [18], that the dimples 
transfer lubricant back into the caviated region once the pocket emerges from that region, and the refilled area is highly influenced by the top-view of dimples.

In brief, the high sample rate friction data have captured the local friction responses that directly linked to the effect of textures, and the results have shown that the converging shape in $x-y$ plane (triangular shape dimples) has a greater local response than the cross-section profile (slope bottom) when the feature is not fully covered by the contact. Steps at the leading edge of dimples are always beneficial for friction reduction irrespective of dimple geometry.

\subsection{Middle stroke friction}

In order to investigate the friction behaviour of the dimple shapes, the mid-stroke friction values were averaged to plot Stribeck curves against dimensionless parameter $\eta V L / W$, where $\eta$ is the lubricant dynamic viscosity, $V$ is the contact speed, $L$ is the roller length and $W$ is the normal load.

In the Stribeck curves shown in Fig. 12, both smooth surface and square flat dimples results are plotted in only one line, since they do not have any directional friction effect, while the other two shapes are plotted in two dashed lines according to the roller's sliding directions (labelled in the figure). The lubrication regime was determined by the lambda ratio calculation, which is detailed in [47]. The test condition is considered as mixed lubrication when the lambda ratio is between 1 and 3. The results show that all the textured surfaces have a similar level of friction reduction, with a maximum friction reduction of about $17 \%$ achieved within boundary lubrication regimes. However, no significant change has been observed in the hydrodynamic lubrication regime, which indicates that hydrodynamic lift was hardly achieved due to the large size of dimples compared to the contact width.

With the dimensionless parameter $\eta V L / W$ increasing to $5 \times 10^{-7}$, the square flat dimple results almost sit in the middle between converging direction and diverging direction of the other two anisotropic specimens' results. For the square sloped textured samples, the largest difference in friction was obtained at $350 \mathrm{~N}$ and $2 \mathrm{~Hz}$. While the biggest difference for triangular flat dimples was achieved at the condition of $100 \mathrm{~N}$ and $10 \mathrm{~Hz}$, with a $7 \%$ difference in friction, as shown in Fig. 12.

To sum up, the total friction reduction effect is observed with all textured samples in boundary lubrication regime. The lubricant retained in the dimples can be considered as a secondary source of lubricant, which can be supplied to the interface as a result of relative movement between interfaces. The mechanism involves Tripp effect, where lubricant being squeezed out of the dimple caused by elastic deformations in the contact region. And the fact that the fluid contact with the moving surface moves at the same velocity as the surface, which can be drawn into surrounding areas to reduce the friction and retard seizing. Since the fluid stored in pockets works as a secondary of source of lubricant, this mechanism is called the 'secondary lubrication'. While the friction behaviour of textured samples in hydrodynamic lubrication regime indicates the pressure build-up effect is not significant when dimple size are much larger than contact width. Although the local friction effect of slope bottom shapes is not obvious, the total friction reduction has proved that the converging bottom has a beneficial effect in lubrication enhancement. Further experiments with transparent materials could be conducted to verify whether cavitation phenomenon enhanced the directional effect.

\section{Conclusions}

In this paper, asymmetric geometry dimples have been fabricated on steel surfaces using laser techniques and their influences on directional friction control have been studied using a TE77 tribometer where lubricated 
reciprocating sliding tests were conducted. Overall, it was found that the diverging and converging feature of the textured surfaces has a significant influence on the friction behaviour across all lubrication regimes. The main conclusions are summarised below.

- The local friction responses of dimples with different top-views indicate that the real contact length between the roller and the plate is crucial to the friction level. Friction increases with growth in the real contact length, and the friction peak occurs during the sudden increase of the real contact length, i.e. at an edge of the dimples, which also suggests a shorter contact length could be beneficial for local friction reduction.

- Directional friction effects are observed in the test of sloped bottom dimples and the converging/diverging shape in the $\mathrm{x}-\mathrm{z}$ plane have a great impact on the amplitude of the mid-stroke friction. The converging shape in this plane is more beneficial for generating lubrication enhancement effect, even the dimple is not fully covered by the contact area.

- For all dimpled surfaces, the maximum friction reduction effect has been generated in the boundary lubrication regime, possibly by providing secondary lubrication as suggested in the literature. The trend in terms of the friction level for the textured surfaces was similar to that of the flat surface in hydrodynamic regime. The result demonstrates that it is difficult to build the pressure up when the dimple size is much larger than the contact width.

- The wear measurements on both the rollers and the flat samples show that the wear was negligible under the test conditions

Acknowledgements: This work was sponsored in part by the National Physical Laboratory in the UK. The authors gratefully acknowledge extremely valuable scientific discussion with our colleagues from nCATS. The laser structuring work has received funding from the European Union's Horizon 2020 research and innovation programme under the Marie Sklodowska-Curie grant agreement no. 644971. Finally, the support for laser processing by the Karlsruhe Nano Micro Facility (http://www.knmf.kit.edu/) is gratefully acknowledged. 


\section{References}

[1] S.-C. Vlădescu, S. Medina, A. V. Olver, I. G. Pegg, and T. Reddyhoff, "Lubricant film thickness and friction force measurements in a laser surface textured reciprocating line contact simulating the piston ring-liner pairing," Tribology International, vol. 98, pp. 317-329, 2016.

[2] B. Bhushan, Modern Tribology Handbook, Two Volume Set: CRC Press, 2000.

[3] D. B. Hamilton, J. A. Walowit, and C. M. Allen, "A theory of lubrication by microirregularities," Journal of Basic Engineering, vol. 88, pp. 177-185, 1966.

[4] I. Etsion and L. Burstein, "A Model for Mechanical Seals With Regular Microsurface Structure," Tribology Transactions, vol. 39, pp. 677-683, 1996.

[5] D. Gropper, L. Wang, and T. J. Harvey, "Hydrodynamic lubrication of textured surfaces: A review of modeling techniques and key findings," Tribology International, vol. 94, pp. 509-529, 2016.

[6] S. Kango, R. K. Sharma, and R. K. Pandey, "Thermal analysis of microtextured journal bearing using non-Newtonian rheology of lubricant and JFO boundary conditions," Tribology International, vol. 69, pp. 19-29, 1// 2014.

[7] A. Bogdan, "Mechanical Seals With Sliding Surface Texture - Model Fluid Flow and Some Aspects of the Laser Forming of the Texture," Procedia engineering, vol. 39, pp. 51-62, 2012.

[8] V. G. Marian, D. Gabriel, G. Knoll, and S. Filippone, "Theoretical and Experimental Analysis of a Laser Textured Thrust Bearing," Tribology Letters, vol. 44, p. 335, 2011.

[9] Y. Zhou, H. Zhu, W. Tang, C. Ma, and W. Zhang, "Development of the theoretical model for the optimal design of surface texturing on cylinder liner," Tribology International, vol. 52, pp. 1-6, 8// 2012.

[10] A. KOVALCHENKO, O. AJAYI, A. ERDEMIR, and G. FENSKE, "The Effect of Laser Texturing of Steel Surfaces and Speed-Load Parameters on the Transition of Lubrication Regime from Boundary to Hydrodynamic," Tribology Transactions, vol. 47, pp. 299-307, 2004.

[11] B. Podgornik, L. M. Vilhena, M. Sedlaček, Z. Rek, and I. Žun, "Effectiveness and design of surface texturing for different lubrication regimes," Meccanica, vol. 47, pp. 1613-1622, 2012.

[12] M. Scaraggi, F. P. Mezzapesa, G. Carbone, A. Ancona, and L. Tricarico, "Friction Properties of Lubricated Laser-MicroTextured-Surfaces: An Experimental Study from Boundary- to Hydrodynamic-Lubrication," Tribology Letters, vol. 49, pp. 117-125, 2013.

[13] D. Braun, C. Greiner, J. Schneider, and P. Gumbsch, "Efficiency of laser surface texturing in the reduction of friction under mixed lubrication," Tribology International, vol. 77, pp. 142-147, 2014.

[14] M. Scaraggi, F. P. Mezzapesa, G. Carbone, A. Ancona, D. Sorgente, and P. M. Lugarà, "Minimize friction of lubricated laser-microtextured-surfaces by tuning microholes depth," Tribology International, vol. 75, pp. 123-127, 7// 2014.

[15] A. Ronen and I. Etsion, "Friction-Reducing Surface-Texturing in Reciprocating Automotive Components," Tribology Transactions, vol. 44, pp. 359-366, 2001.

[16] G. Ryk, Y. Kligerman, and I. Etsion, "Experimental Investigation of Laser Surface Texturing for Reciprocating Automotive Components," Tribology Transactions, vol. 45, pp. 444-449, 2002/01/01 2002.

[17] H. L. Costa and I. M. Hutchings, "Hydrodynamic lubrication of textured steel surfaces under reciprocating sliding conditions," Tribology International, vol. 40, pp. 1227-1238, 8// 2007.

[18] S.-C. Vladescu, A. V. Olver, I. G.Pegg, and T. Reddyhoff, "The effects of surface texture in reciprocating contacts - an experimental study," Tribology International, vol. 82, pp. 28-42, 2015.

[19] S.-C. Vlădescu, S. Medina, A. V. Olver, I. G. Pegg, and T. Reddyhoff, "The Transient Friction Response of a Laser-Textured, Reciprocating Contact to the Entrainment of Individual Pockets," Tribology Letters, vol. 62, p. 12, 2016.

[20] X. Lu and M. M. Khonsari, "An experimental investigation of dimple effect on the stribeck curve of journal bearings," Tribology Letters, vol. 27, pp. 169-176, 2007.

[21] I. Etsion, G. Halperin, V. Brizmer, and Y. Kligerman, "Experimental Investigation of Laser Surface Textured Parallel Thrust Bearings," Tribology Letters, vol. 17, pp. 295-300, 2004.

[22] Y. Qiu and M.M.Khonsari, "Experimental investigation of tribological performance of laser textured stainless steelrings," Tribology International, vol. 44, pp. 635-644, 2011. 
[23] Y. Henry, J. Bouyer, and M. Fillon, "An experimental analysis of the hydrodynamic contribution of textured thrust bearings during steady-state operation: A comparison with the untextured parallel surface configuration," Proceedings of the Institution of Mechanical Engineers,

[24] X. Q. Yu, S. He, and R. L. Cai, "Frictional characteristics of mechanical seals with a lasertextured seal face," Journal of Materials Processing Technology, vol. 129, pp. 463-466, 10/11/ 2002.

[25] A. Kovalchenko, O. Ajayi, A. Erdemir, G. Fenske, and I. Etsion, "The effect of laser surface texturing on transitions in lubrication regimes during unidirectional sliding contact," Tribology International, vol. 38, pp. 219-225, 2005.

[26] L. Wang, "Use of structured surfaces for friction and wear control on bearing surfaces," Surface Topography: Metrology and Properties, vol. 2, p. 043001, 2014.

[27] I. Krupka, P.Svoboda, and M.Hartl, "Effect of surface topography on mixed lubrication film formation during start up under rolling / sliding conditions," Tribology International, vol. 43, p. 1035 1042, 2010.

[28] C. Gu, X. Meng, Y. Xie, and Y. Yang, "Effects of surface texturing on ring/liner friction under starved lubrication," Tribology International, vol. 94, pp. 591-605, 2016.

[29] M. Fowell, A. V. Olver, A. D. Gosman, H. A. Spikes, and I. Pegg, "Entrainment and Inlet Suction: Two Mechanisms of Hydrodynamic Lubrication in Textured Bearings," Journal of Tribology, vol. 129, p. 336, 2007.

[30] A. Gherca, A. Fatu, M. Hajjam, and P. Maspeyrot, "Effects of surface texturing in steady-state and transient flow conditions: Two-dimensional numerical simulation using a mass-conserving cavitation model," Proc IMechE Part J: J Engineering Tribology, vol. 229, pp. 505-522, 2015.

[31] M. Scaraggi, "Lubrication of textured surfaces: A general theory for flow and shear stress factors," Physical Review, vol. E, p. 026314, 2012.

[32] M. Arghir, N. Roucou, M. Helene, and J. Frene, "Theoretical Analysis of the Incompressible Laminar Flow in a Macro-Roughness Cell," Journal of Tribology, vol. 125, 2003.

[33] J. Zhang and Y. Meng, "Direct Observation of Cavitation Phenomenon and Hydrodynamic Lubrication Analysis of Textured Surfaces," Tribology Letters, vol. 46, pp. 147-158, 2012.

[34] C. Greiner, M. Schäfer, U. Popp, and P. Gumbsch, "Contact Splitting and the Effect of Dimple Depth on Static Friction of Textured Surfaces," ACS Applied Materials \& Interfaces, vol. 6, pp. 7986-7990, 2014/06/11 2014.

[35] M. Qiu, BretR.Minson, and BartRaeymaekers, "The effect of texture shape on the friction coefficient and stiffness of gas-lubricated parallel slider bearings," Tribology International, vol. 67, pp. 278-288, 2013.

[36] W. Wang, Z. Huang, D. Shen, L. Kong, and S. Li, "The effect of triangle-shaped surface textures on the performance of the lubricated point-contacts," Journal of Tribology, vol. 135, pp. 1-11, 2013.

[37] Y. L. Zhang, X. G. Zhang, and G. Matsoukas, "Numerical study of surface texturing for improving tribological properties of ultra-high molecular weight polyethylene," Biosurface and Biotribology, vol. 1, pp. 270-277, 2015.

[38] F. Guo, X. Jia, L. Wang, and Y. Wang, "The effect of axial position of contact zone on the performance of radial lip seals with a texturing shaft surface," Tribology International, vol. 97, pp. 499-508, 2016.

[39] H. Zhang, M. Hu, G. Dong, D. Zhang, and K. Chin, "A mixed lubrication model for studying tribological behaviors of surface texturing," 41st Leeds-Lyon Symposium on Tribology - Integrated Tribology, vol. 93, pp. 583-592, 2016.

[40] X. Wang, M. Giovannini, Y. Xing, M. Kang, and K. Ehmann, "Fabrication and tribological behaviors of corner-cube-like dimple arrays produced by laser surface texturing on medical needles," Tribology International, vol. 92, p. 553558, 2015.

[41] H. L. Costa and I. M. Hutchings, "Hydrodynamic lubrication of textured steel surfaces under reciprocating sliding conditions," Tribology International, vol. 40, pp. 1227-1238, 2007.

[42] C. Shen and M. M. Khonsari, "Texture shape optimization for seal-like parallel surfaces: theory and experiment," Tribology Transactions, vol. online, 2016. 
[43] T. Nanbu, N. Ren, Y. Yasuda, D. Zhu, and J. Wang, "Micro-Textures in Concentrated Conformal-Contact Lubrication: Effects of Texture Bottom Shape and Surface Relative Motion," Tribology Letters, vol. 29, pp. 241-252, 2008.

[44] J. Han, L. Fang, J. Sun, Y. Wang, S. Ge, and H. Zhu, "Hydrodynamic Lubrication of Surfaces with Asymmetric Microdimple," Tribology Transactions, vol. 54, pp. 607-615, 2011.

[45] C. Shen and M. M. Khonsari, "Effect of dimple's internal structure on hydrodynamic lubrication," Tribology Letters, vol. 52, pp. 415-430, 2013.

[46] J. K. Schuh and R. H. Ewoldt, "Asymmetric surface textures decrease friction with Newtonian fluids in full film lubricated sliding contact," Tribology International, vol. 97, pp. 490-498, 2016.

[47] P. Lu, R. Wood, M. Gee, L. Wang, and W. Pfleging, "The Friction Reducing Effect of SquareShaped Surface Textures under Lubricated Line-Contacts-An Experimental Study," Lubricants, vol. 4, p. 26, 2016.

[48] J. Pröll, H. Kim, Piqué, H. J. Seifert, and W. Pfleging, "Laser-printing and femtosecond-laser structuring of LiMn2O4 composite cathodes for Li-ion microbatteries," Journal of Power Sources, vol. 255, pp. 116-124, 2014.

[49] D. Dowson and G. R. Higginson, Elasto-hydrodynamic lubrication: the fundamentals of roller and gear lubrication: Pergamon Press, 1966.

[50] H. Nishikawa, K. Handa, and M. Kaneta, "Behavior of EHL Films in Reciprocating Motion," JSME international journal. Ser. C, Dynamics, control, robotics, design and manufacturing, vol. 38, pp. 558-567, 1995/09/15 1995.

[51] B. Zhang, W. Huang, J. Wang, and X. Wang, "Comparison of the effects of surface texture on the surfaces of steel and UHMWPE," Tribology International, vol. 65, pp. 138-145, 9// 2013. 


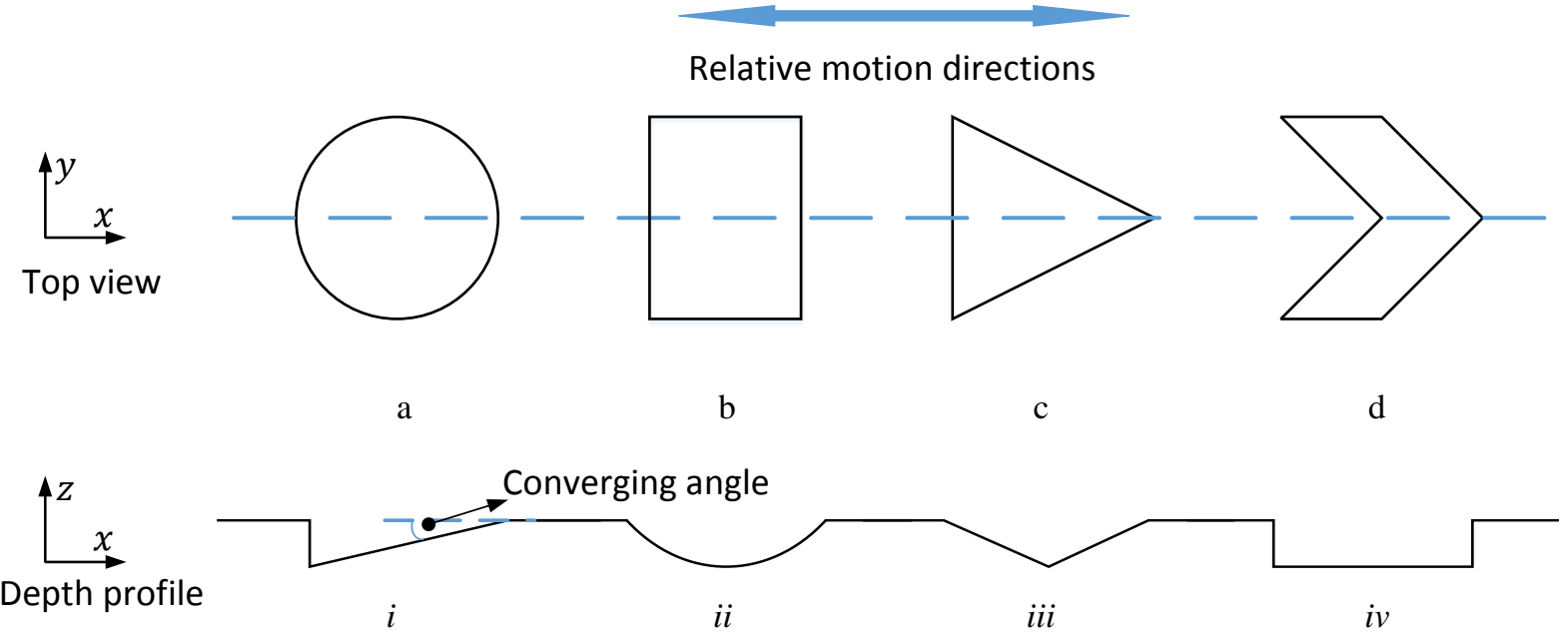

Fig.1 Surface texturing shapes examples: (a) circular; (b) rectangular; (c) triangular; (d) chevron; (i) slope bottom;

(ii) sephere bottom; (iii) triangular slope bottom; (iv) flat bottom 


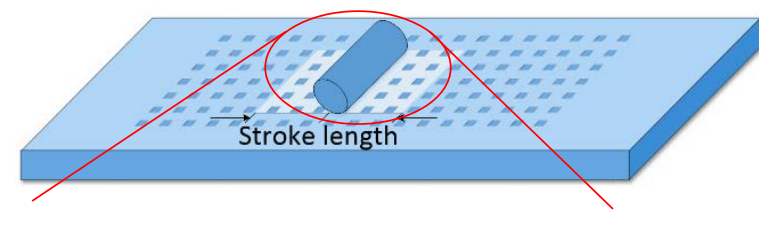

b

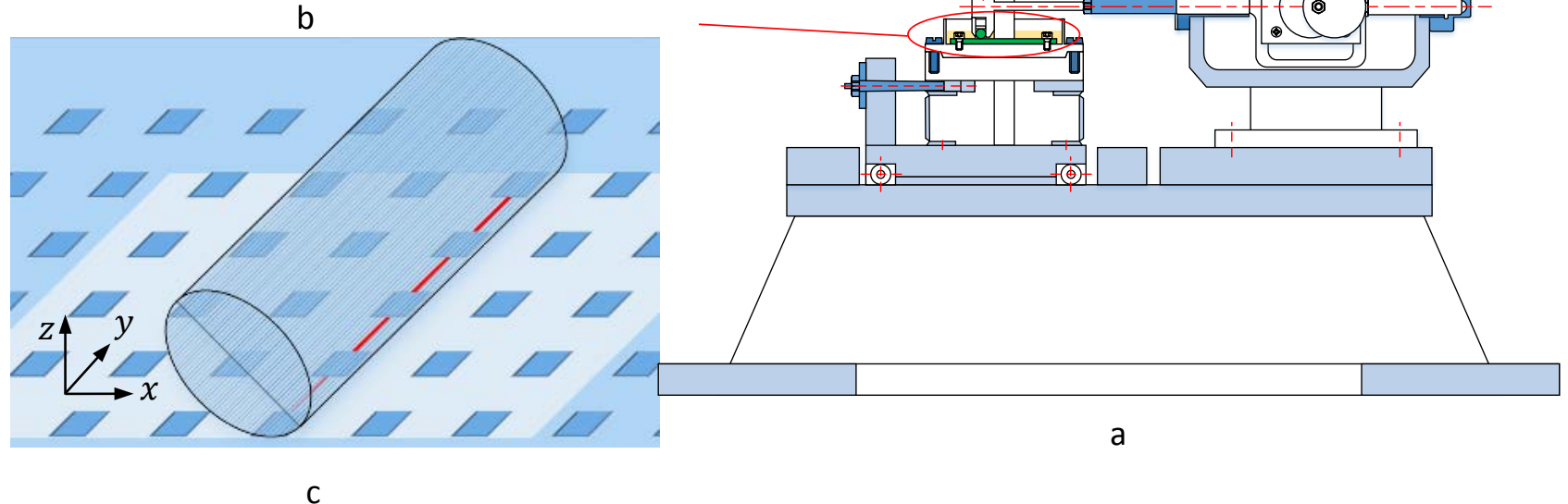

Fig.2 Experimental setup of the Plint TE-77 reciprocating tribometer 


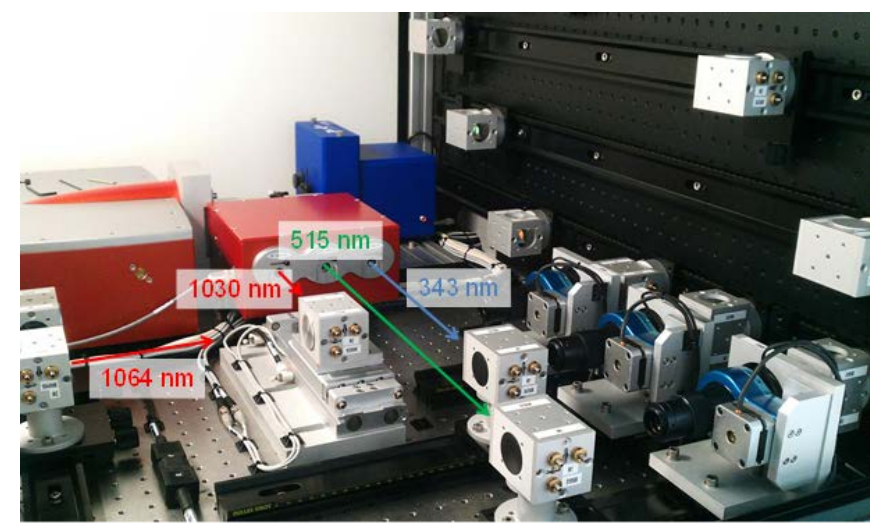

a

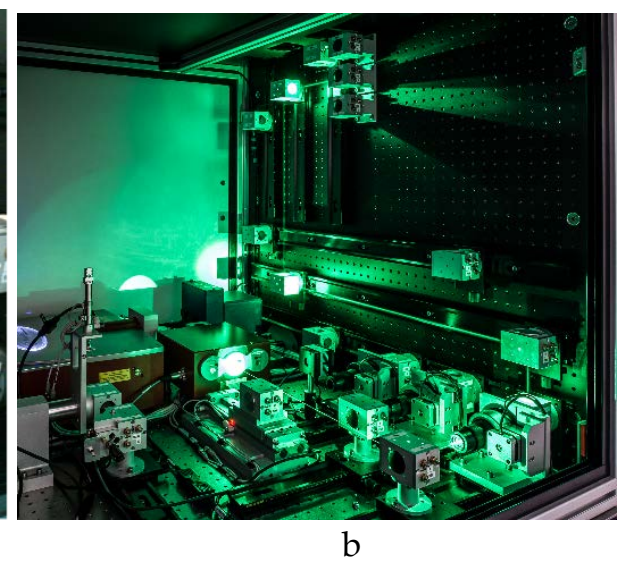

Fig. 3 (a) Optical beam path of the used laser workstation and (b) laser (515 nm) in operation 


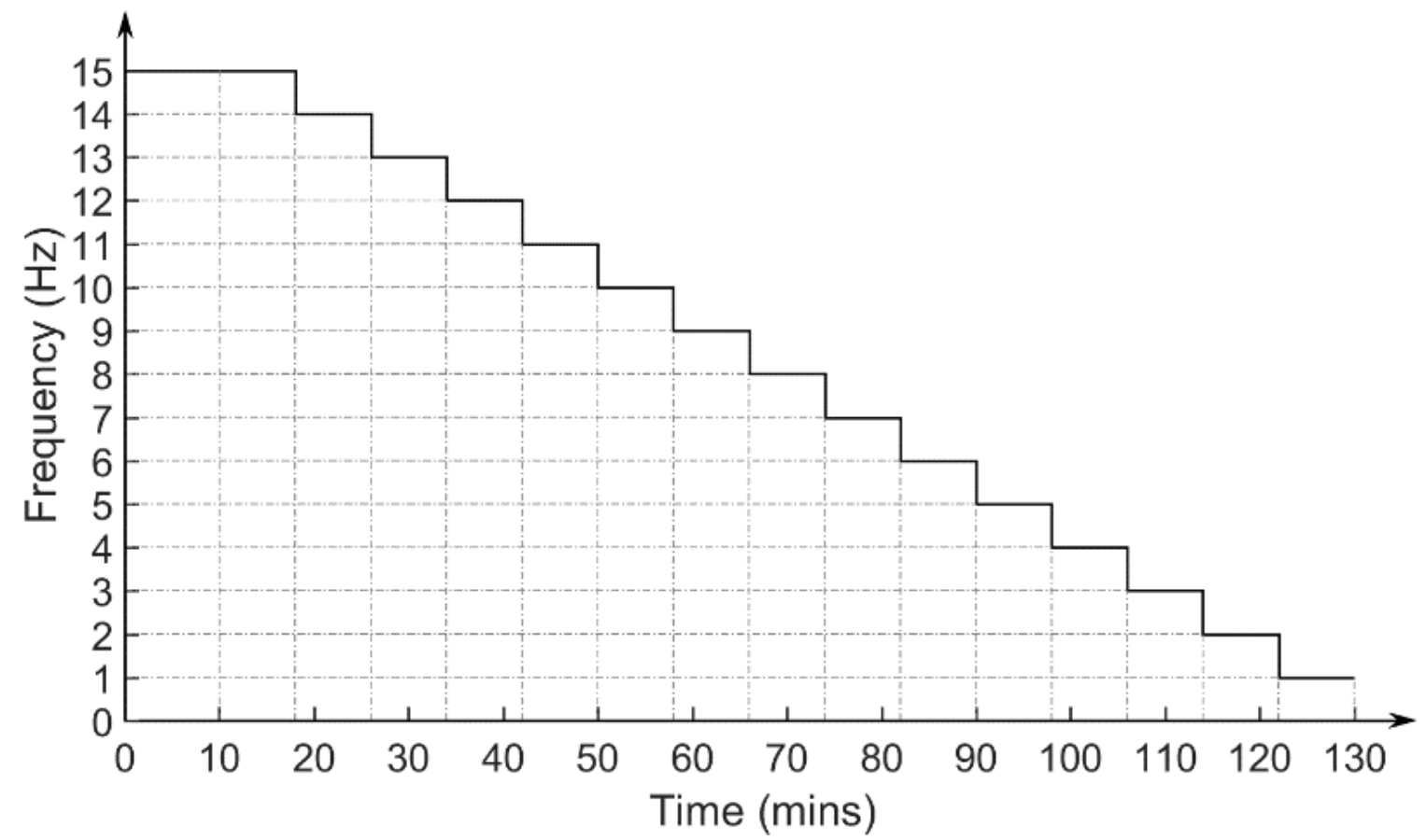

Fig. 4 Test procedure (frequency variation against time) 


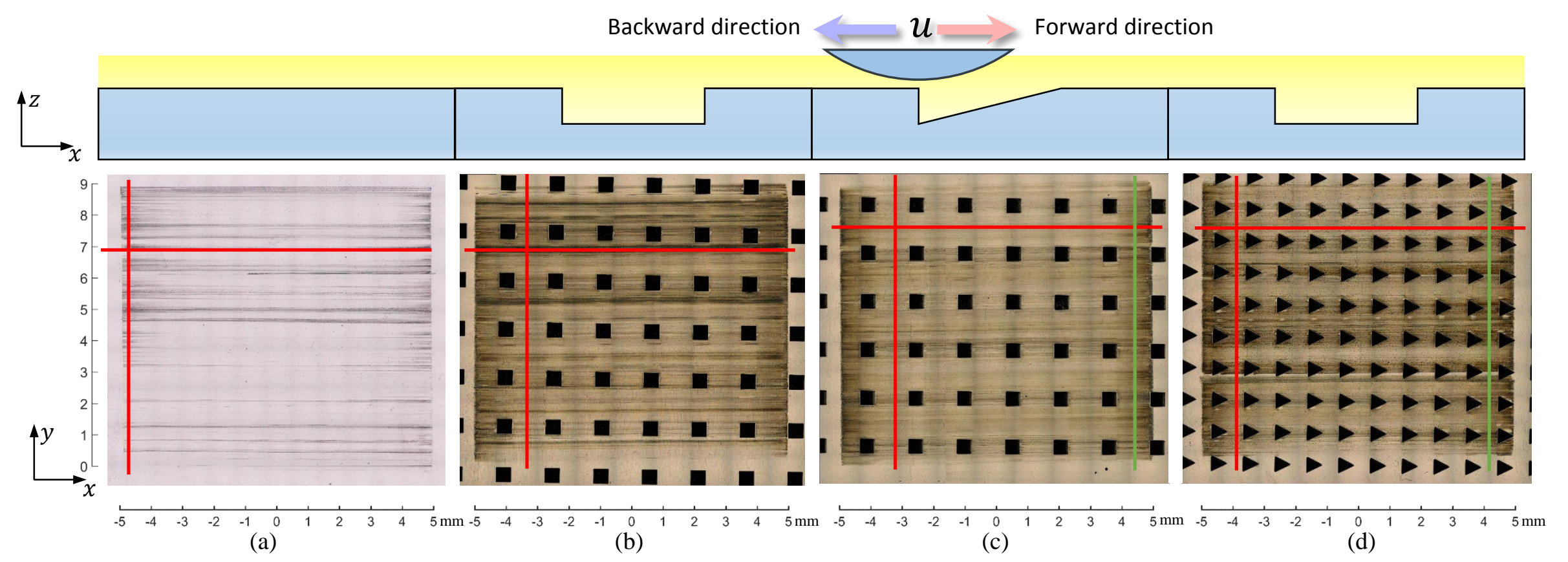

Fig. 5 Wear track measurements of smooth and textured plate specimen (a) Smooth surface (b) Square flat dimples(c) Square slope dimples (d) Triangular flat dimples 


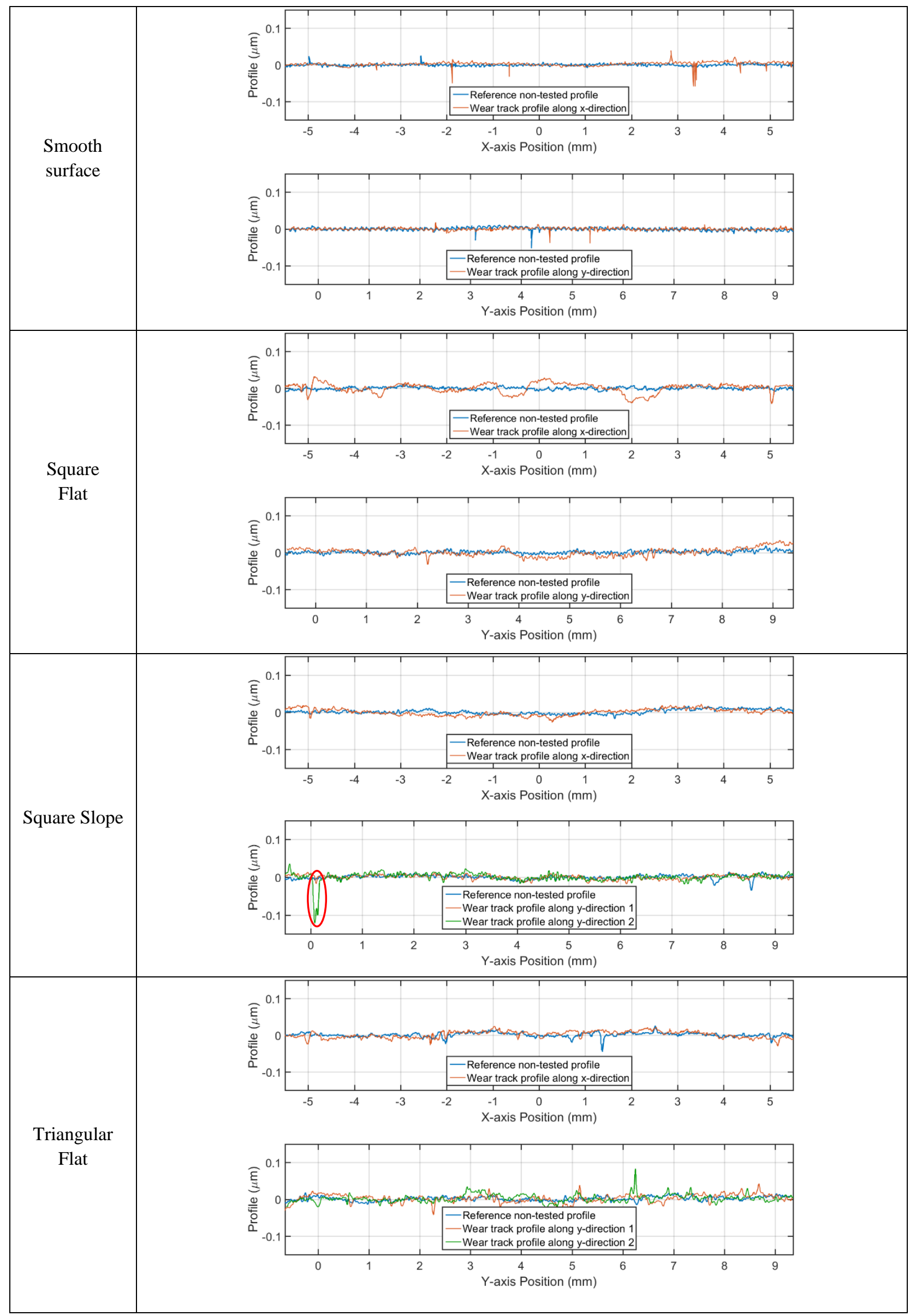

Fig. 6 Wear track profiles of smooth and textured plate specimen 


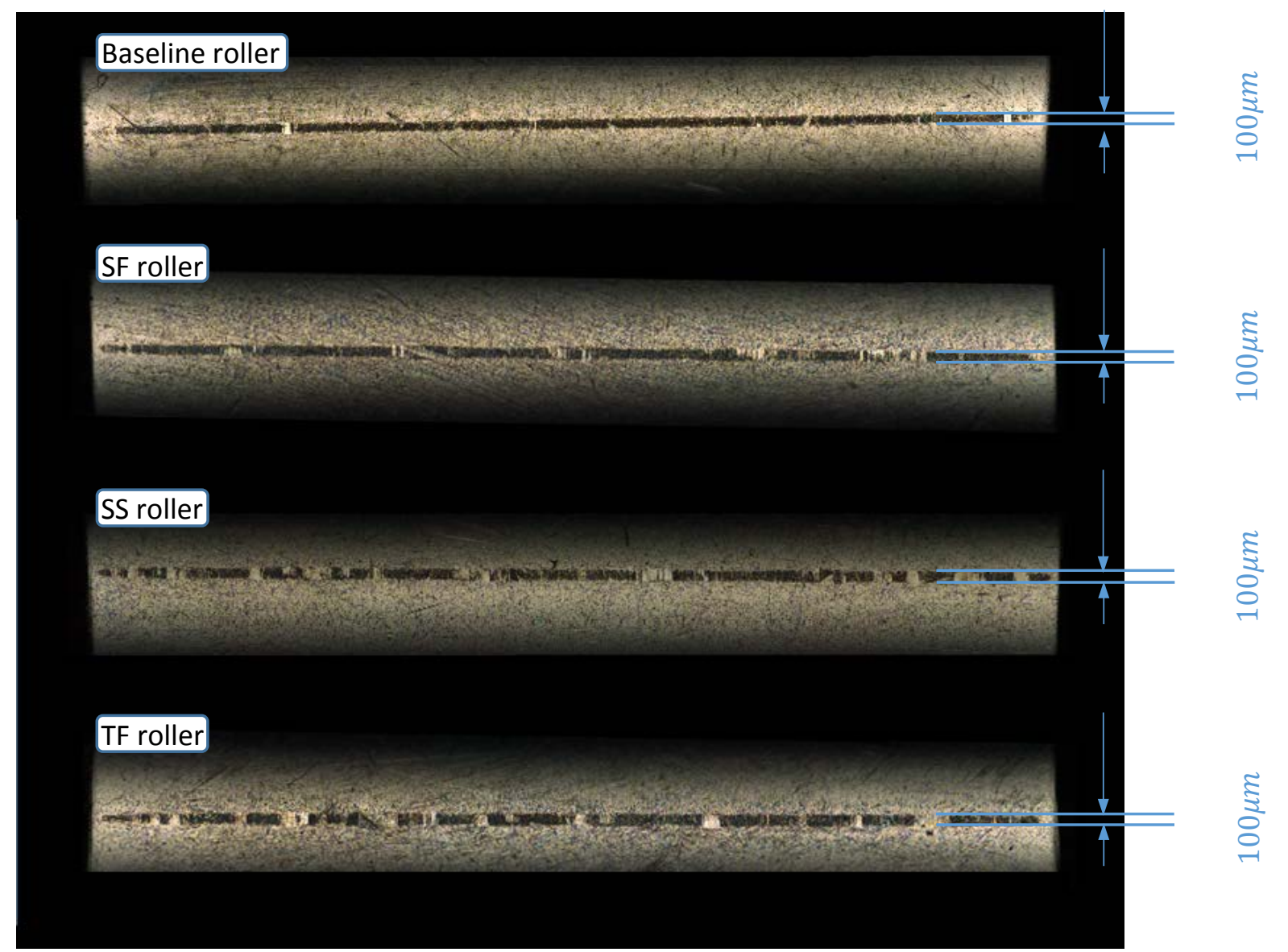

Fig. 7 Wear scar mensurements of cylinders tested with smooth/textured specimens 


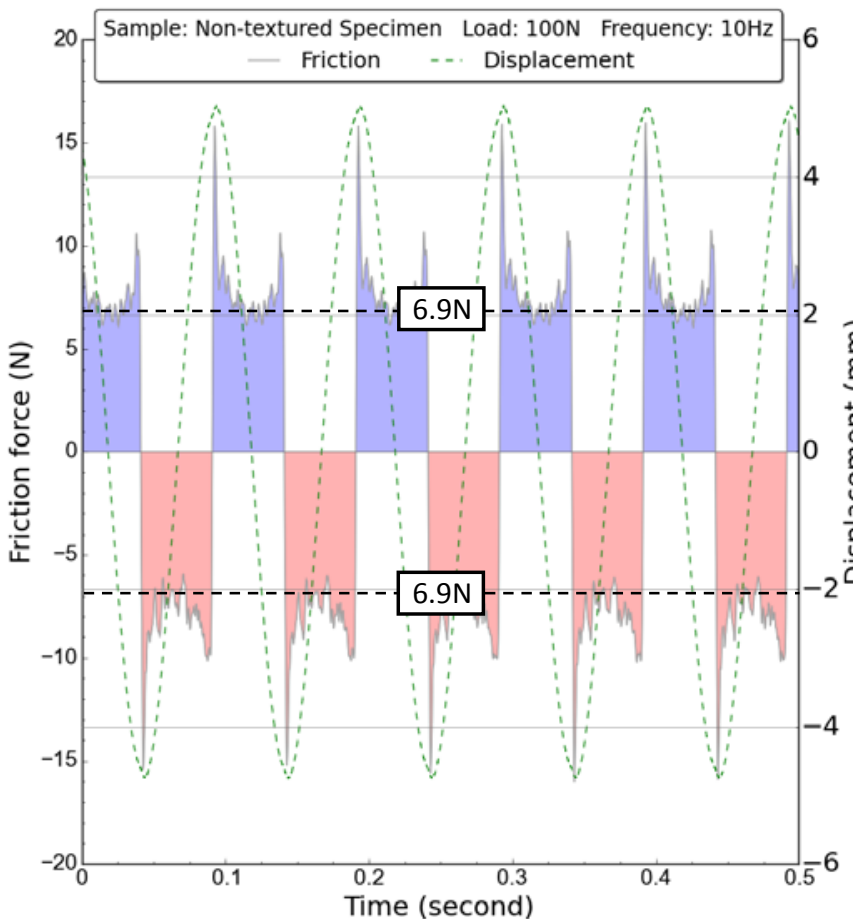

(a)

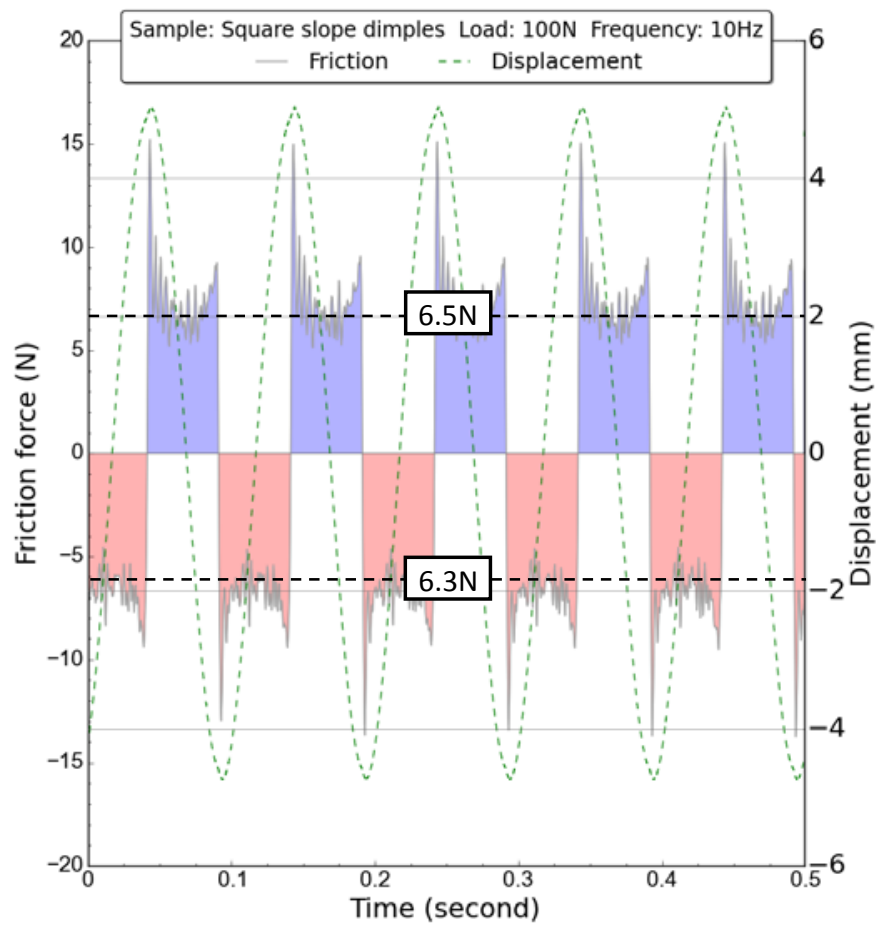

(c)

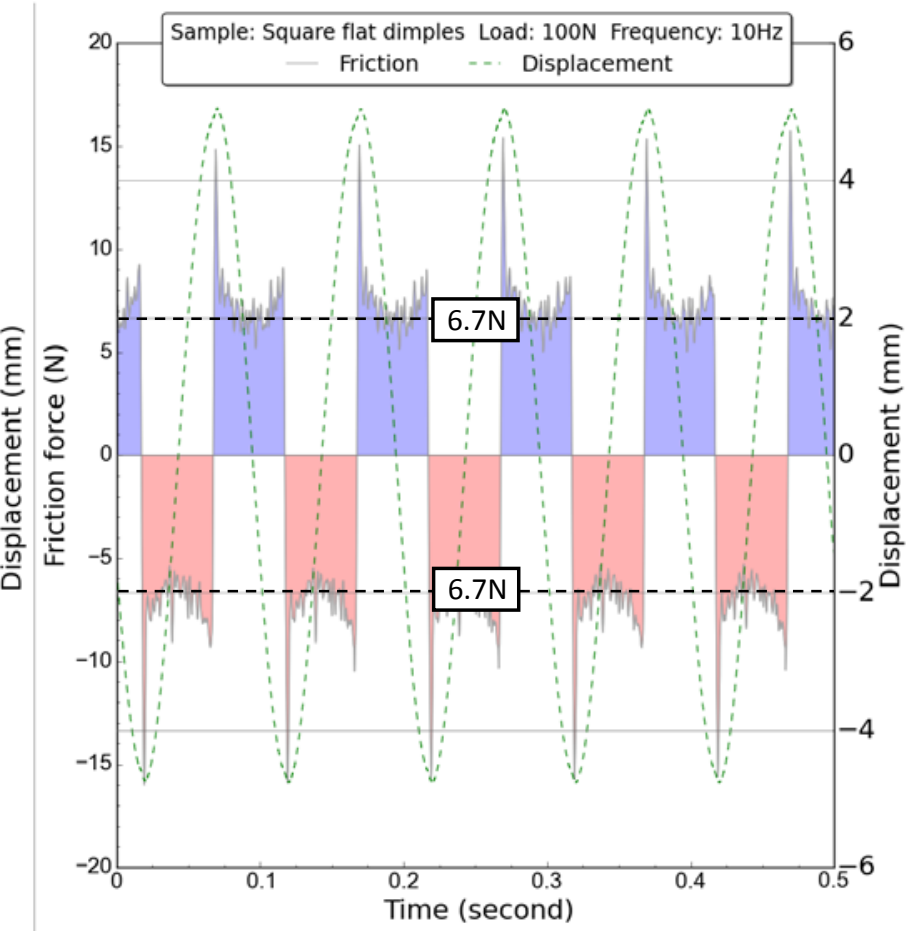

(b)

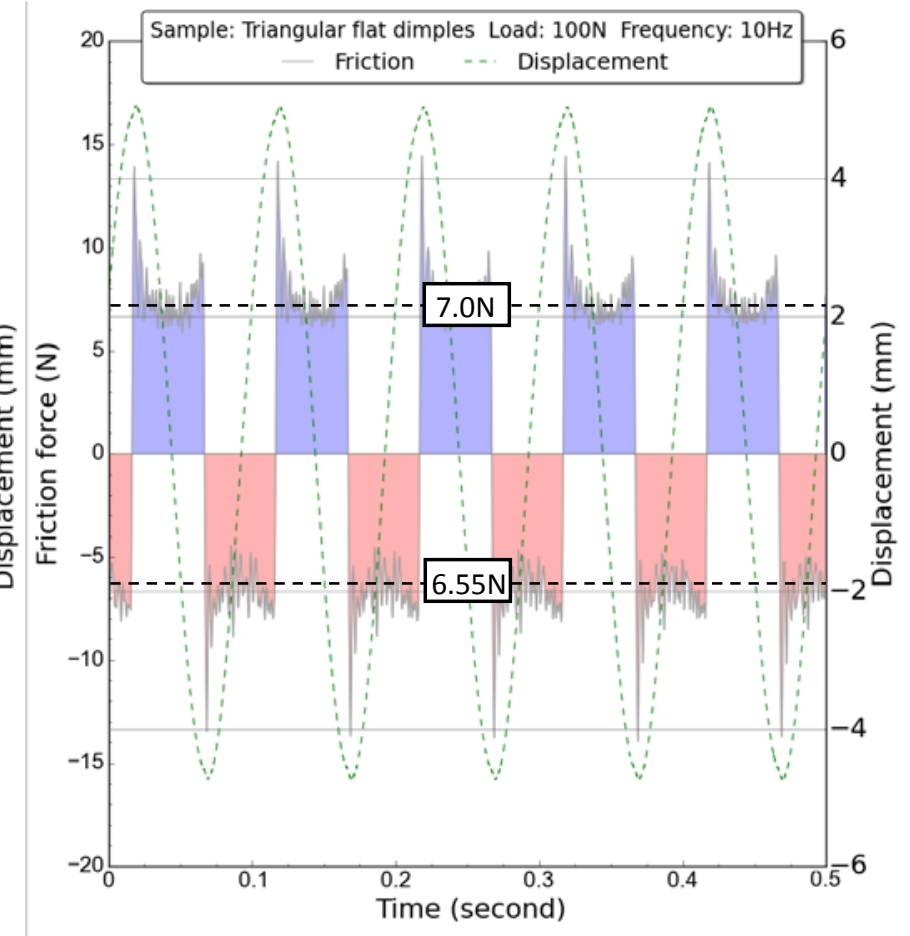

(d)

Fig. 8 Half-second data for non-textured specimen and three pattern designs under load 100N, 10Hz (a) Smooth surface (b) Square flat dimples(c) Square slope dimples (d) Triangular flat dimples 
Smooth surface

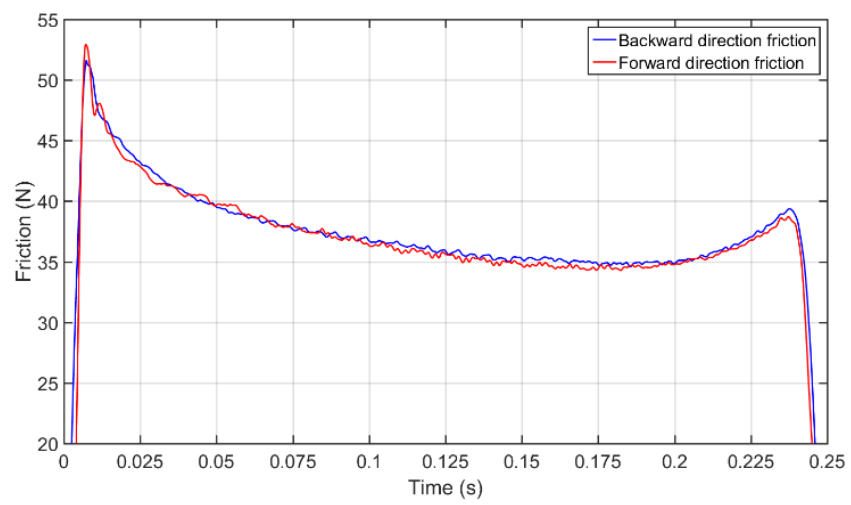

Square slope dimples

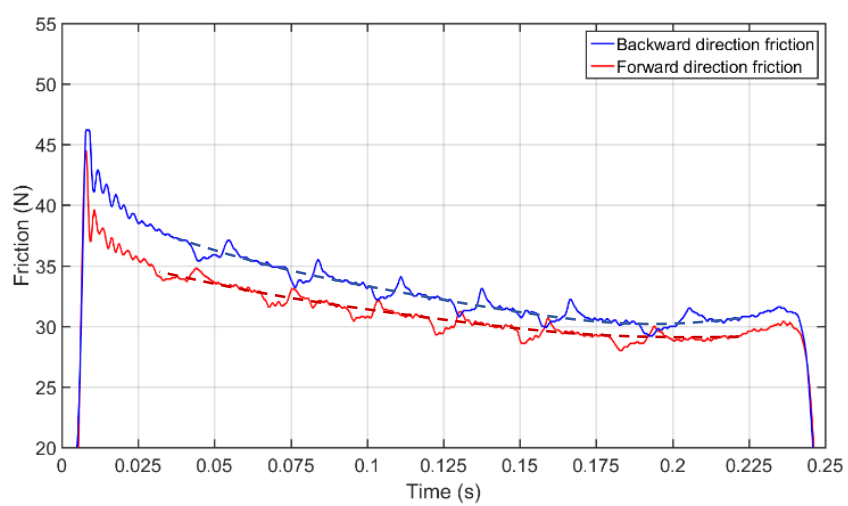

Square flat dimples

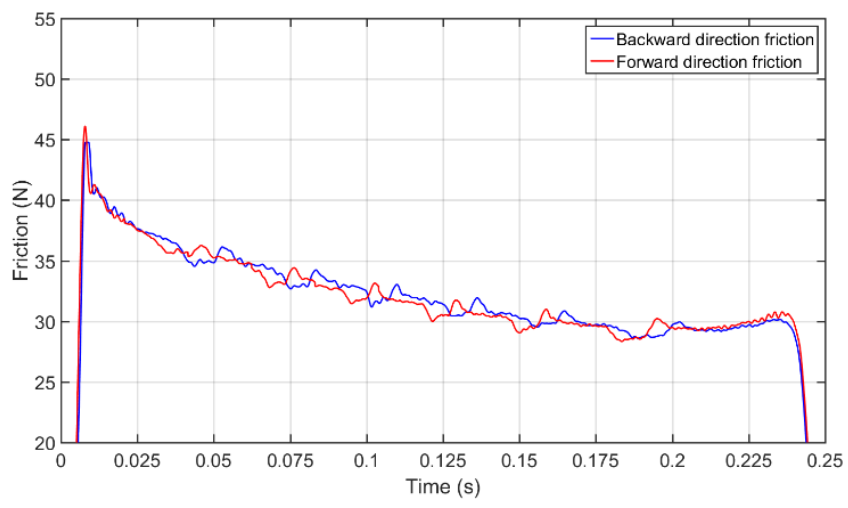

Triangular flat dimples

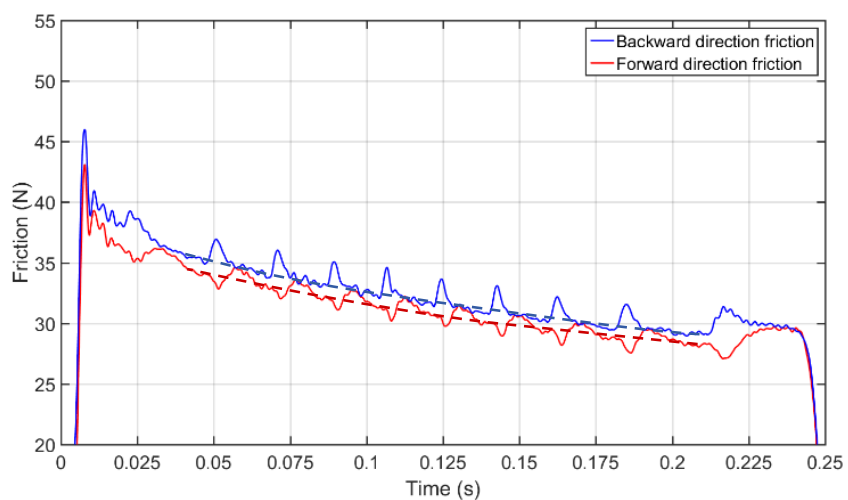

Fig. 9 Single stroke friction force verse time under the boundary lubrication regime (Load: 350N, Frequency: 2Hz) (a) Smooth surface (b) Square flat dimples(c) Square slope dimples (d) Triangular flat dimples 
Roller sliding towards forward direction

a

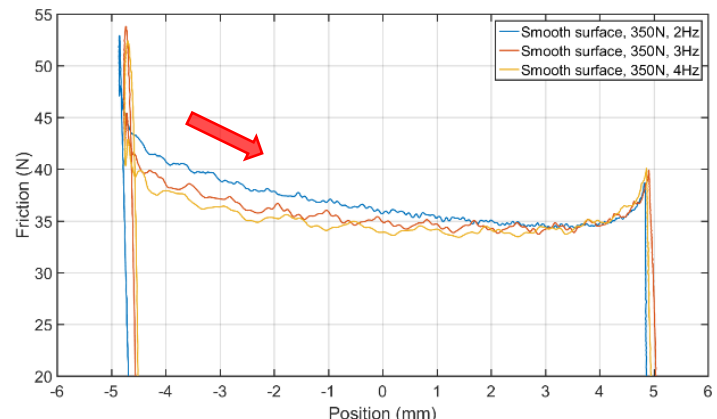

b

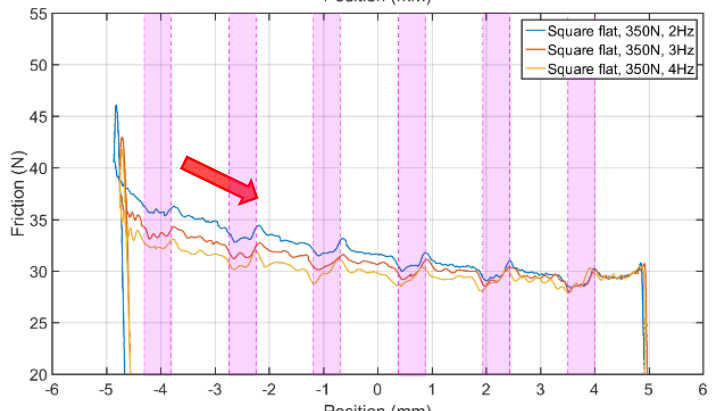

C

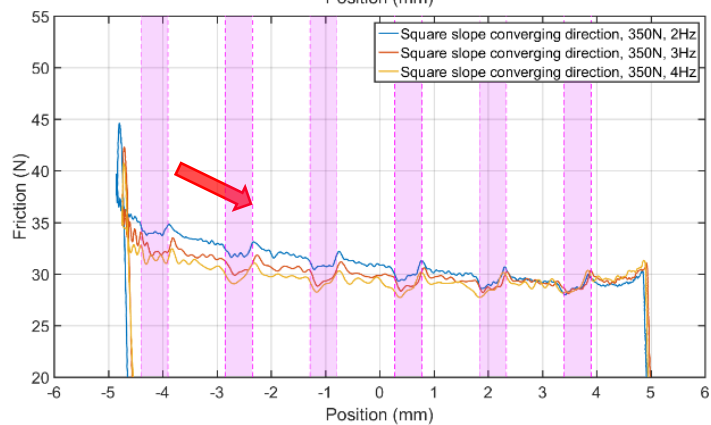

d

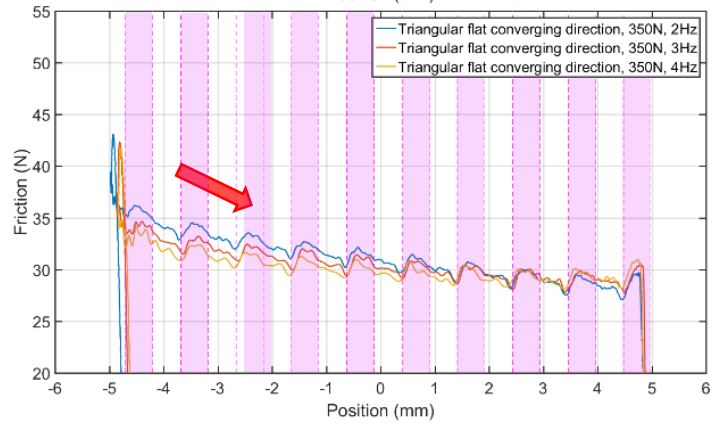

Roller sliding towards backward direction
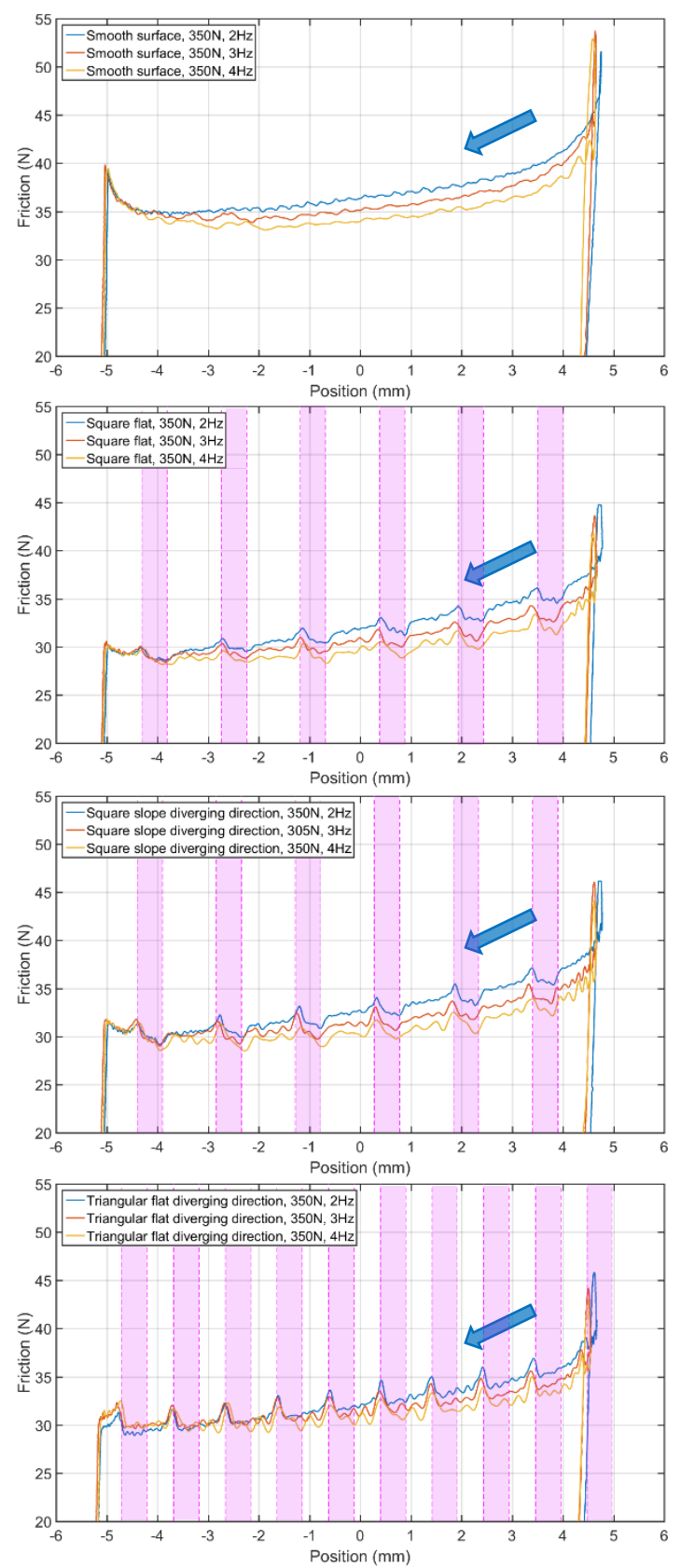

Fig. 10 Single stroke friction force verse roller position under various sliding frequency (Load:350N Frequency:1Hz, 3Hz, 4Hz) (a) Smooth surface (b) Square flat dimples(c) Square slope dimples (d) Triangular flat dimples 


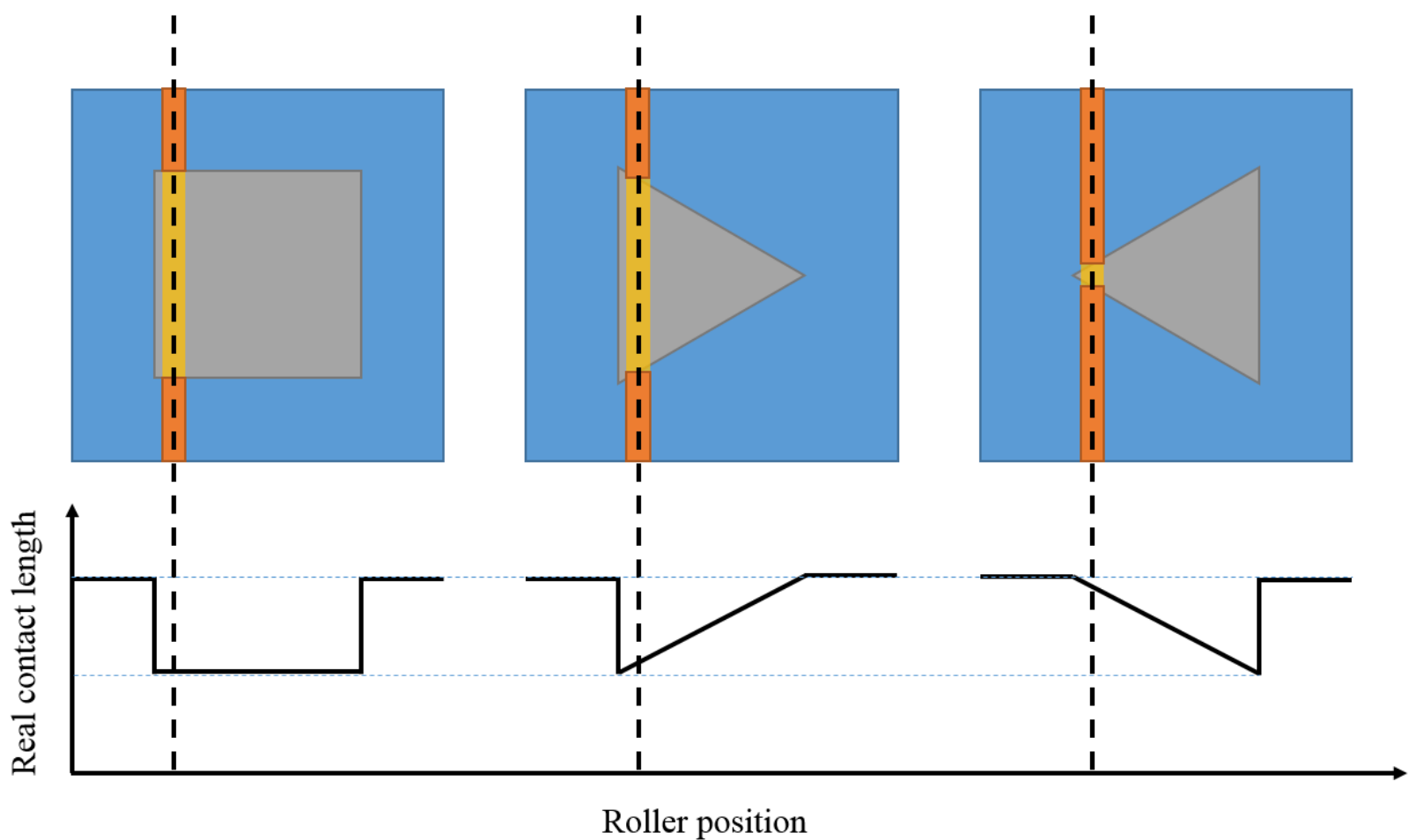

Fig. 11 Real contact length variation of textures with square and triangular top-view shapes 


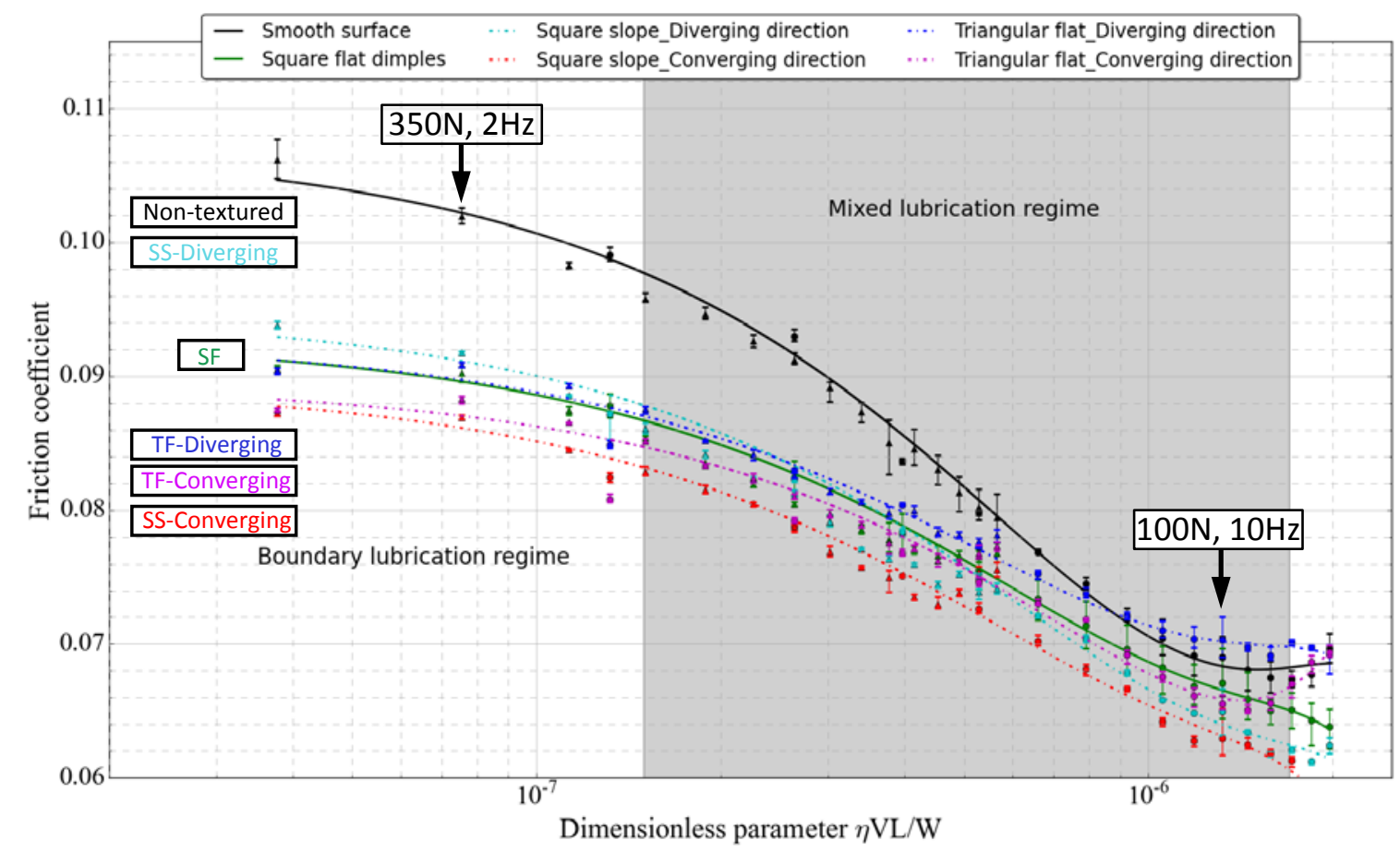

Fig. 12 Stribeck curves of textured and non-textured specimens 
Table 1.

Geometric parameters of the texture on plate specimens

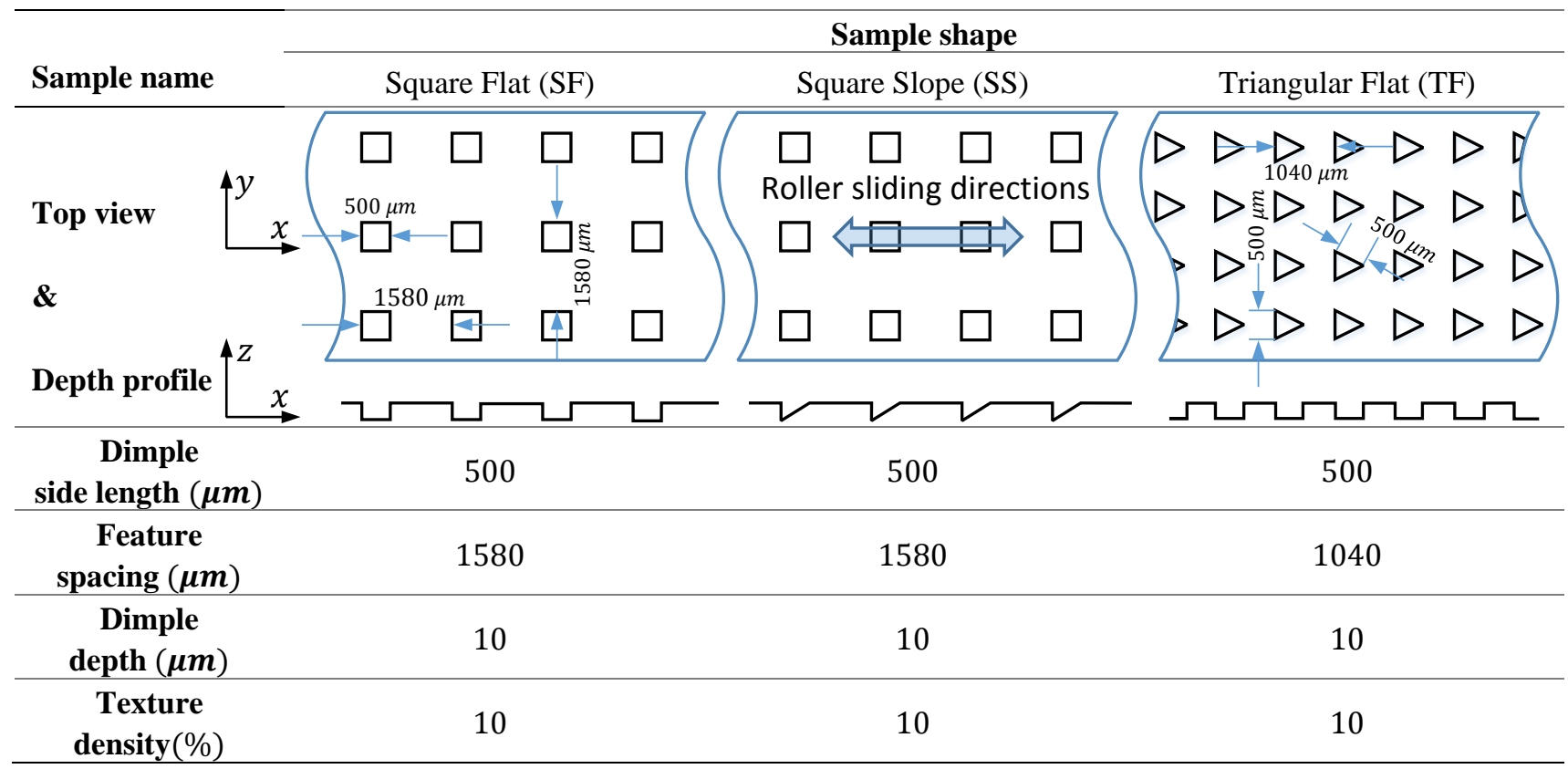


Table 2.

Profile measurements of the texture on plate specimens

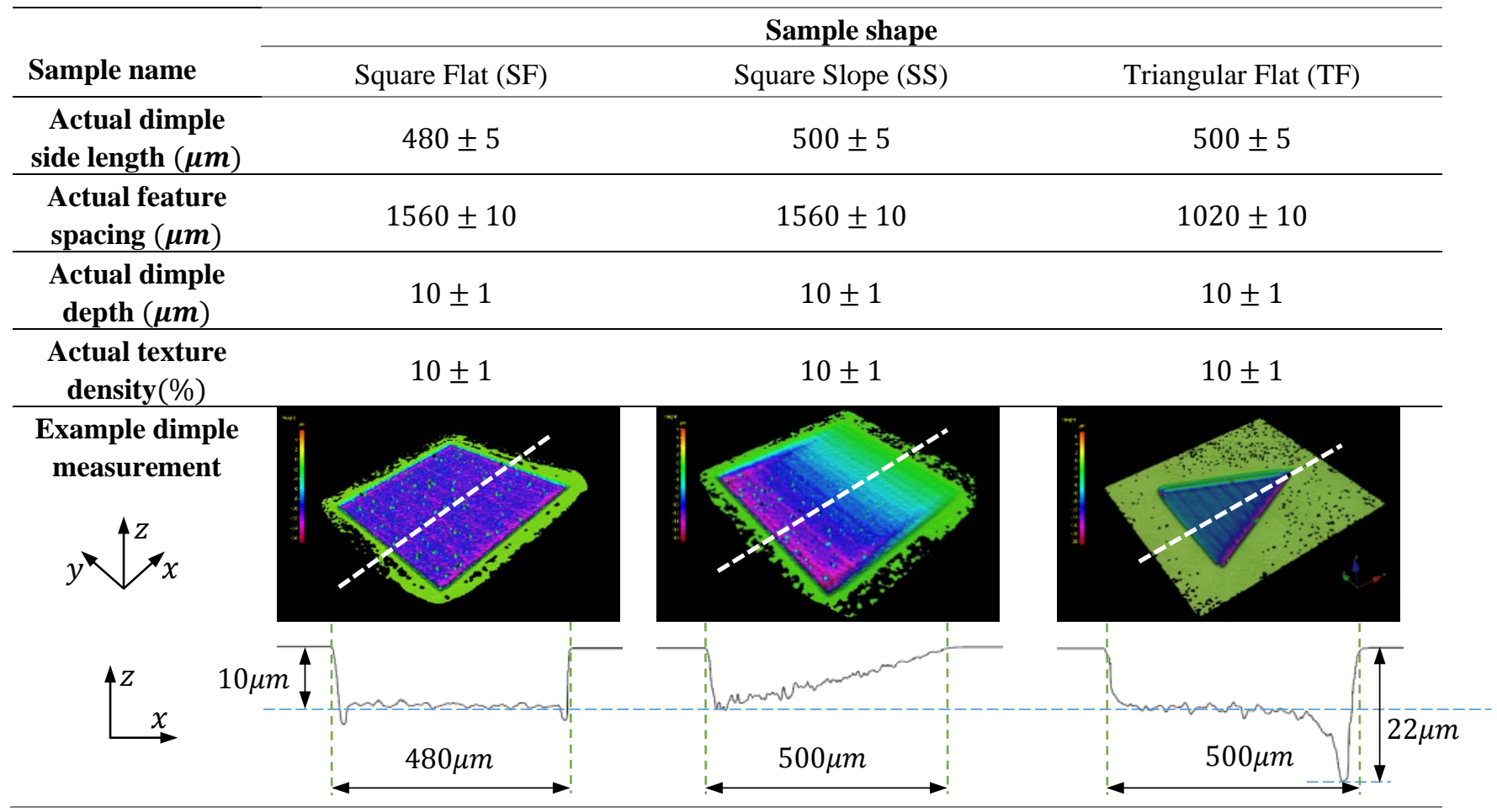




\section{Table 3.}

Dimple edges position against wear scar

\begin{tabular}{llll}
\hline Name & Square flat & Square slope & Triangular flat \\
\hline $\begin{array}{l}\text { Total dimples } \\
\text { in wear scar }\end{array}$ & 6 & 6 & 10 \\
\hline $\begin{array}{l}\text { Left edge } \\
\text { positions } \\
\text { (mm) }\end{array}$ & $\begin{array}{l}-4.3,-2.74,-1.18,-0.38, \\
1.94,3.5\end{array}$ & $\begin{array}{l}-4.35,-2.8,-1.25,0.3, \\
1.85,3.4\end{array}$ & $\begin{array}{l}-4.7,-3.68,-2.66,-1.64,-0.62,0.4, \\
1.42,2.44,3.46,4.48\end{array}$ \\
$\begin{array}{l}\text { Right edge } \\
\text { positions } \\
(\mathbf{m m})\end{array}$ & $-3.82,-2.26,-0.7,0.86$, & $-3.85,-2.3,-0.75,0.8$, & $-4.2,-3.18,-2.16,-1.14,-0.12,0.9$, \\
\hline
\end{tabular}


Table. 4

Friction force measurements under load 350N, $2 \mathrm{~Hz}$ with trend subtracted

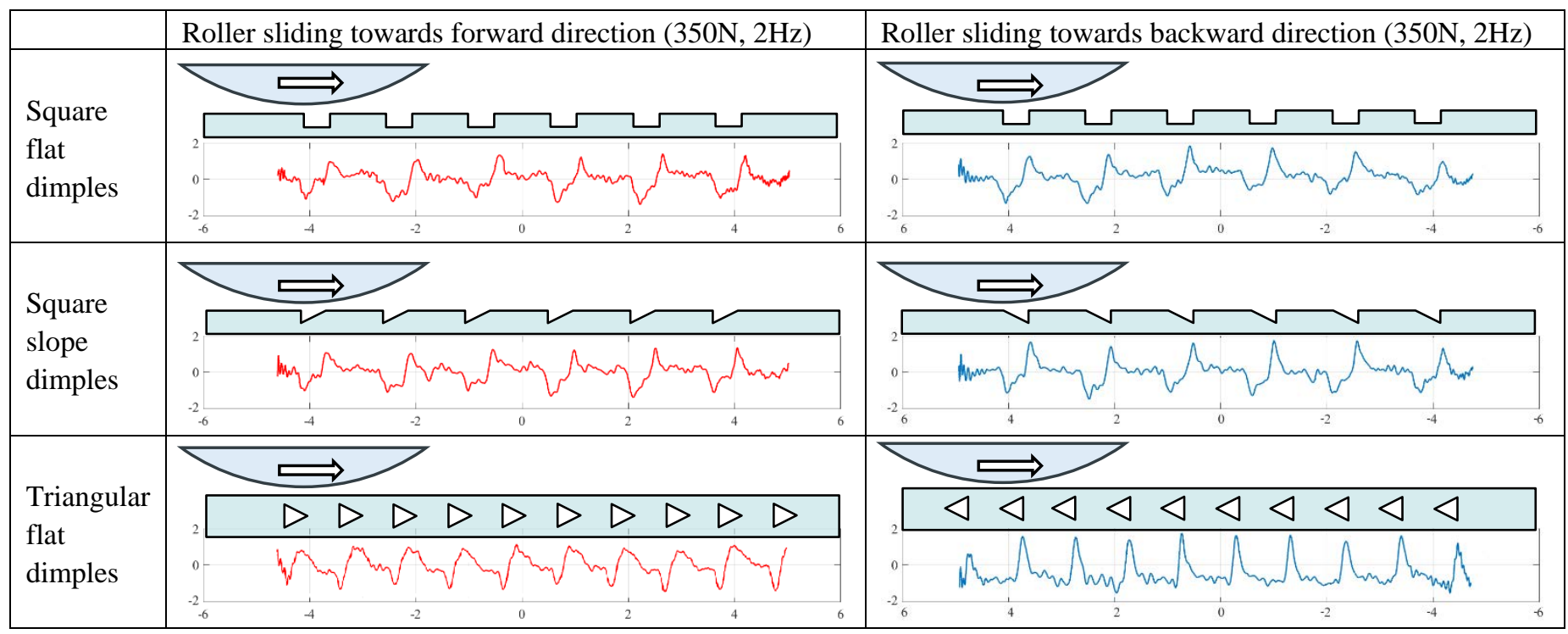

